Check for updates

Cite this: RSC Adv., 2019, 9, 22823

Received 23rd May 2019

Accepted 18th July 2019

DOI: 10.1039/c9ra03890f

rsc.li/rsc-advances

\title{
Constraint spaces in carbon materials
}

\author{
Hiroyuki Itoi, (DD *a Hiroyuki Muramatsu (DD ${ }^{\text {b }}$ and Michio Inagaki ${ }^{\mathrm{c}}$
}

Nano-sized pores in carbon materials are recently known to give certain constraints to the encapsulated materials by keeping them inside, accompanied with some changes in their structure, morphology, stability, etc. Consequently, nano-sized pores endow the constrained materials with improved performances in comparison with those prepared by conventional processes. These pores may be called "constraint spaces" in carbon materials. Here, we review the experimental results related to these constraint spaces by classifying as nanochannels in carbon nanotubes, nanopores and nanochannels in various porous carbons, and the spaces created by carbon coating

\section{Introduction}

Recently, carbon materials have attracted attention in a wide range of fields, from materials in scientific research to industrial products for various applications, such as carbon nanotubes, fullerenes, graphene, and carbon nanodots, in addition to carbon fibers, porous carbons, carbon black, high-density graphite blocks, graphite sheets, etc. ${ }^{\mathbf{1} 2}$ One of the characteristics of carbon materials is the formation of pores with a wide range of sizes and morphologies. Carbon nanotubes have channels with well-defined and nano-sized diameters, of which the walls consist of almost perfect graphene layers although they are severely curved. The diameters of the channels are homogeneous when prepared through a batch synthesis and can be tuned by the synthesis conditions. Meanwhile, other porous carbons, such as activated carbon, contain various sizes of pores from micropores with a size of less than $1 \mathrm{~nm}$ to macropores with a size of more than $50 \mathrm{~nm}$, with various morphologies. The walls of these pores are composed of aggregates of small crystallites with a graphitic structure and/or a few-layer graphene in some cases, and not only basal planes but also edge sites are exposed on the walls. The development in the techniques of precursor design by blending polymers (polymer-blend method) $^{3}$ and of carbonization by using various templates (template-assisted carbonization) ${ }^{\mathbf{4}, \mathbf{5}}$ can control pore sizes, volumes, and morphologies more easily and with much higher carbon yield than the conventional techniques, such as the so-called activation techniques based on oxidation of the carbon matrix. The formation of channel-like and orderly

${ }^{a}$ Department of Applied Chemistry, Aichi Institute of Technology, Yachigusa 1247, Yakusa-cho, Toyota, 470-0392 Japan.E-mail: itoi-hiroyuki@aitech.ac.jp

${ }^{b}$ Faculty of Engineering, Shinshu University, 4-17-1 Wakasato, Nagano, 380-8553 Japan

${ }^{c}$ Professor Emeritus of Hokkaido University, 228-7399 Nakagawa, Hosoe-cho, Kita-ku, Hamamatsu, 431-1304 Japan aligned pores can be realized by selecting appropriate templates, such as zeolites and mesoporous silica.

These pores and channels of carbon materials have played important roles in their applications, such as electrochemical capacitor electrodes by forming electric double-layers on a large surface area for energy storage, adsorbents of polluting species in air and water for environment remediation, etc. The interlayer spaces in graphite crystals are also used to accommodate active materials, the products being called graphite intercalation compounds, (e.g., by using lithium ions in rechargeable batteries). In these cases, the pores, channels, and interlayer spaces of graphite work as storage media of functional materials. Recently, however, some researches demonstrated experimentally that the pores and channels of carbon materials work to endow the encapsulated functional materials with performances either improved or different from those of the bulk or prepared by conventional processes (e.g., powder, films), as well as to enable the reactions of encapsulated materials, which are impossible outside the pores or channels. In other words, these pores and channels give certain constraints to the materials by keeping them inside, accompanied by some changes in their structure, morphology, stability, properties, etc., and therefore can be called "constraint spaces" in carbon materials. In the present review, we try to summarize the experimental results supposedly supported by these constraint spaces of carbon nanotubes and porous carbons. In addition to the pores and channels mentioned above, carbon coating processes of functional materials are included here, because some experimental results suggest certain constraints from the carbon walls to the coated materials.

\section{In carbon nanotubes}

Carbon nanotubes (CNTs) provide long and straight channels with well-defined and uniform diameters. CNTs have been reported to work as constraint spaces for collapsing encapsulated fullerenes to form the wall of CNTs inside and improving the 
electrochemical activities of encapsulated alkaline metal-doped fullerenes, iodine, sulfur, and organic molecules (e.g., quinones). In addition, water molecules undergo structural change or phase transition in the constraint spaces of CNTs.

\section{(a) Fullerenes}

Encapsulation of fullerenes, mostly $\mathrm{C}_{60}$ and $\mathrm{C}_{70}$, into single-wall carbon nanotubes $\left(\mathrm{C}_{60} @\right.$ @WCNT and $\left.\mathrm{C}_{70} @ S W C N T\right)$ was experimentally observed in the products of laser ablation of graphite impregnated by $\mathrm{Co} / \mathrm{Ni}$ catalyst and in those of carbon arc discharge using $\mathrm{Ni} / \mathrm{Y}$ catalyst, ${ }^{6,7}$ the product being called "bucky-peapod" or simply "peapod". By using diameter-selected SWCNTs, encapsulations of $\mathrm{C}_{60}$ and $\mathrm{C}_{70}$ were performed by heat treatment at $650{ }^{\circ} \mathrm{C}$ to yield high density fullerene chains in each SWCNT, with filling factors of 85 and $72 \%$, respectively. ${ }^{8}$ The distance between $\mathrm{C}_{60}$ cages in the CNTs was $0.95 \mathrm{~nm}$, which was shorter than that in the crystal with face-centered cubic closest packing $(1.00 \mathrm{~nm})$ and longer than that in the polymer of $\mathrm{C}_{60}(0.92 \mathrm{~nm})$. On the other hand, two different distances of 1.00 and $1.10 \mathrm{~nm}$ between $\mathrm{C}_{70}$ cages were observed for $\mathrm{C}_{70^{-}}$ (aSWCNTs, which were due to morphologies of standing and lying $\mathrm{C}_{70}$ cages, respectively. Encapsulations of $\mathrm{C}_{60}$ and $\mathrm{C}_{70}$ into double-walled and triple-walled carbon nanotubes (DWCNTs and TWCNTs, respectively) were facilitated by reacting CNTs with fullerene vapor at $500{ }^{\circ} \mathrm{C} .{ }^{9}$ The filling factors of both $\mathrm{C}_{60}$ and $\mathrm{C}_{70}$ peapods were about $70 \%$. Theoretical calculations based on the local density approximation in the densityfunctional theory showed that the encapsulating process of $\mathrm{C}_{60}$ into SWCNT is exothermic for the $(10,10)$ CNT, whereas endothermic for the $(8,8)$ and $(9,9)$ CNTs, suggesting that the minimum radius of the nanotube for the encapsulation is $0.64 \mathrm{~nm} .{ }^{10}$ Structural stability of $\mathrm{C}_{60} @$ @WCNTs was examined under high pressures and high temperatures by using in situ synchrotron X-ray diffraction. ${ }^{11,12}$ The diffraction peak at 25.23 $\mathrm{keV}$ (corresponding to the spacing of $0.956 \mathrm{~nm}\left(2 \theta\right.$ of $\left.2.946^{\circ}\right)$ ) reflecting one-dimensional $\mathrm{C}_{60}$ crystals was intensified with increasing pressure up to $10.7 \mathrm{GPa}$ at room temperature and the $\mathrm{C}_{60}-\mathrm{C}_{60}$ distance was progressively shortened from $0.956 \mathrm{~nm}$ at $0.1 \mathrm{MPa}$ down to $0.892 \mathrm{~nm}$ at $10.7 \mathrm{GPa}^{.11}$ By heating up to $1023{ }^{\circ} \mathrm{C}$ under $4 \mathrm{GPa}$, the $\mathrm{C}_{60}-\mathrm{C}_{60}$ distance further reduced to $0.87 \mathrm{~nm}$ as a result of $\mathrm{C}_{60}$ polymerization. ${ }^{12}$ SWCNT peapods of $\mathrm{C}_{60}$ and $\mathrm{C}_{70}$ were synthesized in a high yield using a sublimation method by contacting SWCNTs with fullerene vapors. ${ }^{13}$

The coalescence of $\mathrm{C}_{60}$ inside SWCNTs proceeds at high temperatures. $\mathrm{C}_{60} @$ @WWCNTs were prepared by reacting SWCNTs with $\mathrm{C}_{60}$ vapor at $400{ }^{\circ} \mathrm{C}$ in dry air, and then treated at high temperatures in vacuo $\left(<10^{-6}\right.$ Torr). ${ }^{14}$ Encapsulated $\mathrm{C}_{60}$ molecules are self-assembled to make a chain with nearly uniform center-to-center distances, as shown TEM image in Fig. 1a. $\mathrm{C}_{60}$ molecules remain mostly unchanged in CNTs up to $800{ }^{\circ} \mathrm{C}$ and start to coalesce with adjacent ones to form linked beans and/or short nanotube above $800{ }^{\circ} \mathrm{C}$, as shown on 1000 ${ }^{\circ} \mathrm{C}$-treated one in Fig. 1 b. At $\sim 1200{ }^{\circ} \mathrm{C}$, most $\mathrm{C}_{60}$ molecules coalesce to form tube wall, making this part DWCNTs by retaining the empty single-wall tube partly, as shown in Fig. 1c. After $1200{ }^{\circ} \mathrm{C}$ treatment, no $\mathrm{C}_{60}$ molecules remain and most of
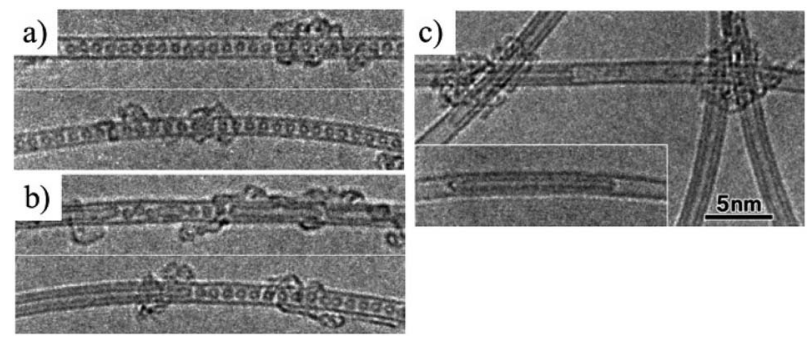

Fig. 1 TEM images of $\mathrm{C}_{60}$-encapsulated SWCNT: (a) as-prepared, (b) after heat treatment at $1000{ }^{\circ} \mathrm{C}$, and (c) after $1200{ }^{\circ} \mathrm{C}$ in vacuo. Adapted from ref. 14 with permission from Elsevier.

tubes are partly changed to double-walled, and in some cases, the inner tubes are terminated by caps (Fig. 1c). The thermal treatment of bucky-peapods is the most effective way for the fabrication of catalyst-free high-purity DWCNTs among the methods including arc-discharge and chemical vapor deposition (CVD) methods using catalysts, particularly to form smalldiameter inner tubes $(0.4-0.7 \mathrm{~nm})$. The diameter of the inner tube synthesized from the peapods of SWCNTs with filling factor of $60-80 \%$ depends on the temperature of synthesis, as shown in Fig. $2 .{ }^{15}$ Almost the same diameter distribution of the inner tubes is achieved by the coalescence of fullerenes up to $1800{ }^{\circ} \mathrm{C}$, but it becomes broad after the heat treatment at $2000{ }^{\circ} \mathrm{C}$, including enlarged diameters due to coalescence of adjacent tubes.

Coalescence of fullerenes in SWCNTs is induced also by electron irradiation to form DWCNTs, which was followed by in situ TEM observations. ${ }^{16}$ DWCNTs are mechanically, thermally, and structurally more stable than SWCNTs, probably because of the buffer-like function of the outer tubes. ${ }^{17}$ The inner tube of DWCNT exhibits unique transport and optical properties such as extremely sharp Raman lines for the radial breathing mode (RBM) of the inner tube, suggesting high crystallinity of the inner tube and highly-unperturbed environment in the interior of the tubes. ${ }^{18}$ Highly crystalline and uniform TWCNTs were also obtained from the heat treatment of DWCNTs-peapods at

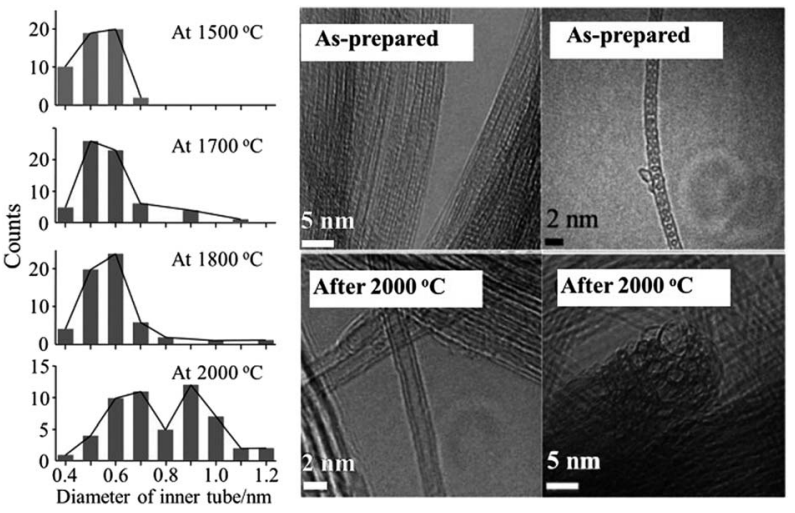

Fig. 2 Distribution of the diameter of inner tube for DWCNTs synthesized at different temperature and high-resolution TEM images of as-prepared peapods and DWCNTs synthesized at $2000{ }^{\circ} \mathrm{C}$. Adapted from ref. 15 with permission from John Wiley and Sons. 
$2000{ }^{\circ} \mathrm{C}$ in $\mathrm{Ar}^{19}$ The DWCNTs were prepared by catalytically grown method, and their diameters were enlarged to the enough interior spaces of 1.2-1.6 $\mathrm{nm}$ for the encapsulation of $\mathrm{C}_{60}$ through the heat treatment at $2400{ }^{\circ} \mathrm{C}$ in $\mathrm{Ar}$ atmosphere. Such a high temperature triggers diameter enlargement process via the coalescence between DWCNTs.

Two adjacent DWCNTs (Fig. 3a) coalesce into off-centered coaxial carbon nanotubes (Fig. 3c) by annealing above $2100{ }^{\circ} \mathrm{C}^{\mathbf{2 0 , 2 1}}$ DWCNTs first merge into bi-cable carbon nanotubes by coalescence of the outer tubes (Fig. 3b), and the resulting inner tubes further coalesce inside a large diameter tube (Fig. 3c). ${ }^{21}$ Eventually, symmetric enlarged DWCNTs appear by more structural rearrangement of encapsulated offcentered inner tube along with the outer tube. The process of coalescence of two DWCNTs and merging into bi-cable CNT were discussed on the bases of detail TEM analyses and molecular dynamic calculations. Coalescence of SWCNTs to multi-walled CNTs was also reported. ${ }^{22}$

Encapsulation of Gd-metallofullerene cages into SWCNTs, which were previously heated at $420{ }^{\circ} \mathrm{C}$ in dry air for $20 \mathrm{~min}$ to open the tube ends, was carried out in a sealed glass ampoule at $500{ }^{\circ} \mathrm{C}$ for $24 \mathrm{~h}^{.23}$ The TEM images of fully encapsulated SWCNTs demonstrated that fullerene molecules were oriented randomly in respect to the tube axis, which could be supposed by observing dark spots due to Gd atoms in the fullerene cages.

K-doping into $\mathrm{C}_{60} @$ @WCNTs was performed by exposing $\mathrm{C}_{60}$ @SWCNTs to potassium vapor at $473 \mathrm{~K}$ over $50 \mathrm{~h} .{ }^{24}$ TEM images before and after K-doping are shown in Fig. 4. After doping, some dark spots in the figures, which are reasonably supposed to be individual $\mathrm{K}$ atoms, are clearly observed inside CNTs and are allocated at the interfullerene sites. Electrochemical insertion/de-insertion of $\mathrm{Li}$ into $\mathrm{C}_{60}$ @SWCNT was carried out in $1 \mathrm{M} \mathrm{LiClO}_{4} /(\mathrm{EC}+\mathrm{DEC})$ over the potential range of $0-3.0 \mathrm{~V},{ }^{25}$ and the cell gave the reversible capacity of 550$610 \mathrm{~mA} \mathrm{~h} \mathrm{~g}^{-1}$, which is slightly larger than the pristine SWCNT (460-490 mA h g ${ }^{-1}$ ), although $\mathrm{C}_{60} @ S W C N T$ and DWCNT showed a large irreversible capacity. The enhancement in the capacity is explained by the following two possibilities, the change in the electronic structure of the SWCNTs and a steric effect from the encapsulated $\mathrm{C}_{60}$. The encapsulated $\mathrm{C}_{60}$ stabilizes the $\mathrm{Li}$ ion desolvated at the entrance of the tubes.

Zn-diphenylporphyrin (Zn-DPP) is not a spherical but a flat molecule, of which size is about $1.0 \mathrm{~nm}$ and somewhat larger than $\mathrm{C}_{60}$ and $\mathrm{C}_{70}$, and possible to be encapsulated into SWCNTs with a diameter distribution from 1.25 to $1.47 \mathrm{~nm}$ at $400{ }^{\circ} \mathrm{C} .{ }^{8}$ In the
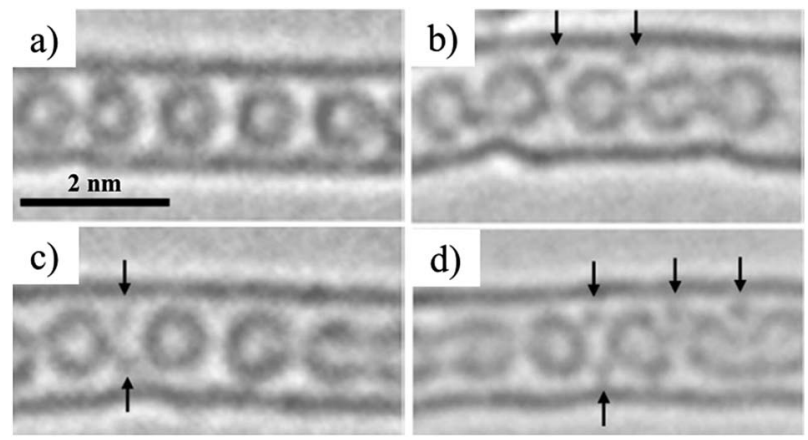

Fig. 4 TEM images of (a) the pristine $\mathrm{C}_{60}$ @ $a$ SWCNTs and (b-d) after Kdoped ones. Adapted from ref. 24 with permission from the American Physical Society.

resultant Zn-DPP@SWCNTs, both Zn-DPP and SWCNT were supposed to be deformed from the experimental facts of a redshift of the $\pi \rightarrow \pi^{*}$ transition in Zn-DPP and a drastic decrease of the radial breathing mode Raman spectrum intensity of SWCNTs.

\section{(b) Iodine}

Encapsulation of iodine into SWCNTs (I@SWCNTs) was shown to be effective to improve their galvanomagnetic properties. ${ }^{26}$ It was performed by heating the mixture of SWCNTs, which were synthesized by arc-discharge method using $\mathrm{Ni} / \mathrm{Y}$ catalyst, with iodine at $150{ }^{\circ} \mathrm{C}$ in an evacuated glass tube. I-encapsulation was confirmed by the shift of Raman G-band from $1594 \mathrm{~cm}^{-1}$ for the pristine SWCNT to $1597 \mathrm{~cm}^{-1}$ for I@SWCNT and an increase in the intensity ratio of D-band to G-band $\left(I_{\mathrm{D}} / I_{\mathrm{G}}\right)$, suggesting the introduction of high structural disorders by I-doping. The replacement of inorganic transparent conductive film, such as indium tin oxide, may be possible with flexible transparent conductive films of SWCNTs by alkali-metal $(\mathrm{K}, \mathrm{Rb})$ or halogen-atom $(\mathrm{Br}, \mathrm{I})$ doping, which can improve electrical conductivity of SWCNTs. Electrochemical Idoping in SWCNTs was performed in a NaI aqueous electrolyte. ${ }^{27}$ The G-band of in situ Raman spectrum for the SWCNTs shifts gradually with an increasing amount of doped I, while tends to be saturated, indicating full I-doping level, as shown in Fig. 5. The electrochemical I-doping level can easily be controlled by tuning the applied potential and time. By reversing the polarity in an electrochemical cell, doped-iodine molecules could be removed completely. To understand the structure of polyiodide ions encapsulated into CNTs and the charge-transfer from CNTs to iodine molecules, in situ Raman spectrum measurements were performed

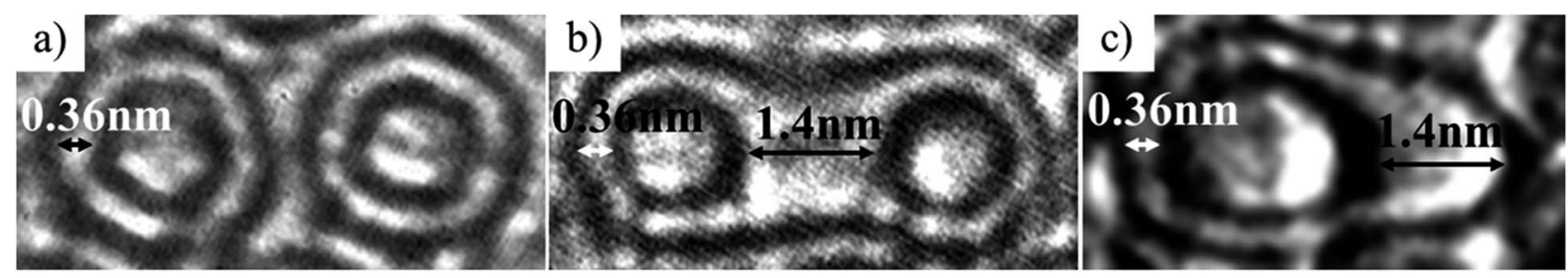

Fig. 3 TEM images on the gradual changes from (a) adjacent DWCNTs, (b) bi-cable structure and (c) off-centered DWCNT during heat treatment at $2100{ }^{\circ} \mathrm{C}$. Adapted from ref. 21 with permission from Elsevier. 


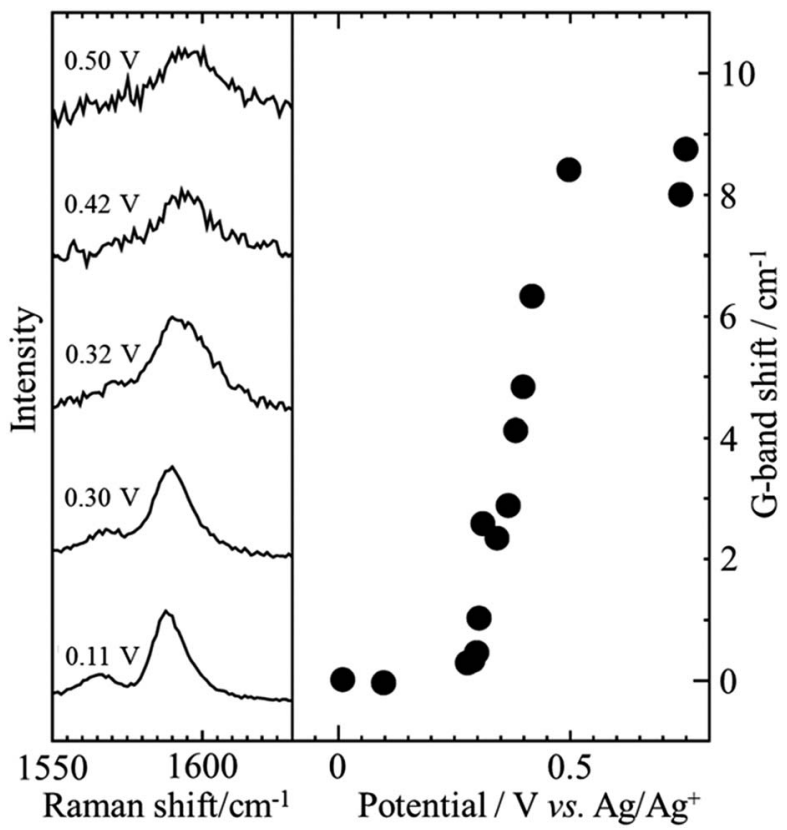

Fig. 5 G-band shift of SWCNTs as a function of applied potential. Adapted from ref. 27 with permission from the PCCP Owner Societies.

on SWCNTs having different tube diameters at low temperatures down to $-100{ }^{\circ} \mathrm{C}^{28}$ The amounts of the encapsulated iodine molecules estimated by TG analysis were $36.6,49.0$ and $50.0 \mathrm{wt} \%$ for the SWCNTs having the averaged diameters of 1.0, 1.5 and $2.5 \mathrm{~nm}$, respectively. The Raman G-band peak position of the SWCNTs shifted toward the higher wavenumber side with decreasing temperature, suggesting that the charge transfer from SWCNTs to encapsulated I molecules increased with decreasing temperature to form polyiodide ions such as $\mathrm{I}_{3}{ }^{-}, \mathrm{I}_{5}{ }^{-}$and $\mathrm{I}_{7}{ }^{-}$.

Crystalline KI nanoparticles were grown in the nanospaces of single-wall carbon nanohorns (SWCNHs) by heating the mixture at $1073 \mathrm{~K}$ in a sealed quartz tube. ${ }^{29}$ The nanospaces of SWCNHs, internal tubular spaces and interparticle micropores, were measured as the volume of 0.50 and $0.11 \mathrm{~cm}^{3} \mathrm{~g}^{-1}$, respectively. The structure of KI crystals encapsulated in SWCNHs had the same as that formed under the pressure above 1.9 GPa in the bulk crystal, suggesting highly constrained state of KI crystals in the nanospaces of SWCNHs.

\section{(c) Sulfur}

In a sealed glass tube at $873 \mathrm{~K}$, sulfur can be encapsulated into SWCNTs and DWCNTs as monoatomic chains with the length up to $160 \mathrm{~nm}$, forming S@SWCNTs and S@DWCNTs. ${ }^{30}$ In Fig. 6a, b and c, high-resolution TEM images are shown: two straight chains in SWCNT, one zigzag chain and one straight chain in DWCNT, respectively. Both straight and zigzag chains were encapsulated inside SWCNT and DWCNT, respectively. The distance $(d)$ between two neighboring $\mathrm{S}$ atoms in both straight and zigzag chains increases gradually with increasing temperature in SWCNTs, as shown in Fig. 6d and e. In DWCNTs, however, $d$ in the chains is slightly smaller than that in SWCNTs at the temperature below $450 \mathrm{~K}$ and it approaches that in SWCNT abruptly above $650 \mathrm{~K}$, suggesting that the S chains are immobilized in the host SWCNTs up to $800 \mathrm{~K}$, in other words, SWCNTs provide the most suitable space for stabilizing the $\mathrm{S}$ chains. These thermodynamic behavior of $\mathrm{S}$ chains in SWCNT and DWCNT shown in Fig. 6d and e, respectively, are quite different from the bulk arrays of $\mathrm{S}_{8}$ molecules, which has the melting point at about $393 \mathrm{~K}$ and boiling point at about $718 \mathrm{~K}$. The sulfur atoms in CNTs were supposed to be bound with covalent character, forming onedimensional crystalline phase, as proved by XRD, and the sulfur chains constrained in the nanotubes were electroconductive under ambient pressure and temperature; the electric resistivity $\rho$ at $300 \mathrm{~K}$ of SWCNTs decreased by the encapsulation of $S$ chains from $1.1 \times 10^{-3}$ to $5.0 \times 10^{-4} \Omega \mathrm{cm}$. By taking into consideration the fact that the bulk $\mathrm{S}$ becomes metallic under ultrahigh pressure more than $90 \mathrm{GPa},{ }^{31}$ encapsulated $\mathrm{S}$ chains are strongly constrained in the spaces of SWCNT.

\section{(d) Organic molecules}

Various organic molecules, tetrakis(dimethylamino)ethylene (TDAE), tetramethyl-tetraselenafulvalene (TMTSF), tetrathiafulvalene (TTF), pentacene, anthracene, 3,5-dinitrobenzonitrile, tetracyano- $p$-quinodimethane (TCNQ) and tetrafluorotetracyano- $p$-quinodimethane $\left(\mathrm{F}_{4} \mathrm{TCNQ}\right)$, were encapsulated into SWCNTs. ${ }^{32}$ Encapsulation was performed simply by heating SWCNTs, which were purified and de-capped with $\mathrm{H}_{2} \mathrm{O}_{2}, \mathrm{HCl}$, and $\mathrm{NaOH}$, with these organic molecules just above their sublimation temperatures in vacuum. Encapsulation (confinement) of organic molecules results in the injection of amphoteric carriers into SWCNTs, which can be controlled by the ionization energy and electron affinity of the encapsulated molecules. As shown in the inset of Fig. 7a, optical absorption spectrum changes by the encapsulation of organic molecules into SWCNT. The intensity of the absorption band at $0.68 \mathrm{~V}$ was normalized by that of the pristine SWCNT, and the intensity ratio, $I_{\text {doped }} / I_{\text {pristine, }}$ was plotted against ionization energy and electron affinity of the molecules in Fig. 7a and b, respectively, showing amphoteric carrier doping characteristics of encapsulated organic molecules. The field-effect-transistor devices of SWCNTs encapsulated by organic molecules revealed that TTFand TMTSF-confined SWCNTs showed n-type behavior, whereas TCNQ-confined SWCNTs showed p-type behavior. These SWCNT semiconductors by confinement of organic molecules have the following advantages: air stability, controllable carrier doping, and simple process for preparation.

Encapsulation of 9,10-anthraquinone (AQ) and 9,10-phenanthrene quinone (PhQ) molecules into SWCNTs was performed by heating their mixture at $200{ }^{\circ} \mathrm{C}$ in an evacuated glasstube. ${ }^{33,34}$ After the heat treatment, AQ@SWCNTs and PhQ@SWCNTs were recovered by washing with organic solvents ( $N, N$-dimethylformamide for AQ and acetone for PhQ) to remove the excess $\mathrm{AQ}$ and $\mathrm{PhQ}$ deposited on the outer surface of the SWCNTs. Self-supported films of AQ@SWCNTs and PhQ@SWCNTs were obtained in this step. Electrochemical measurements for lithium-ion batteries (LIBs) and sodium-ion 
a)

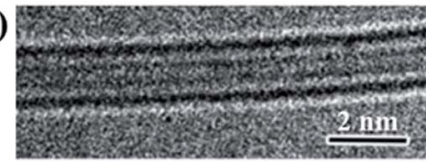

b)

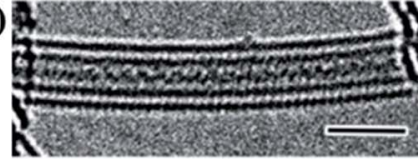

c)

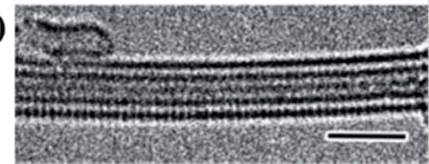

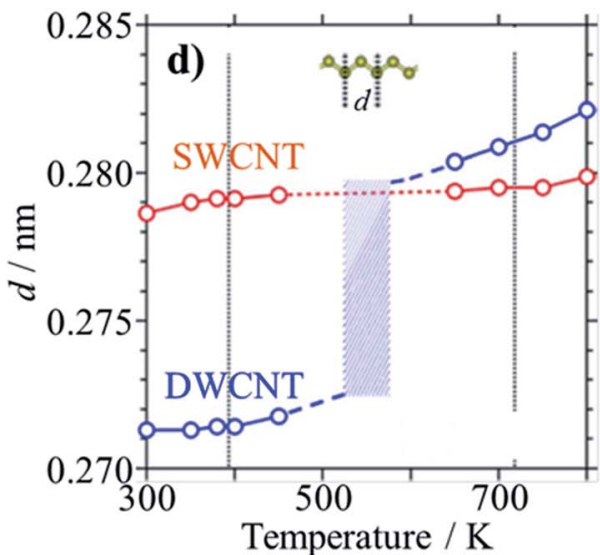

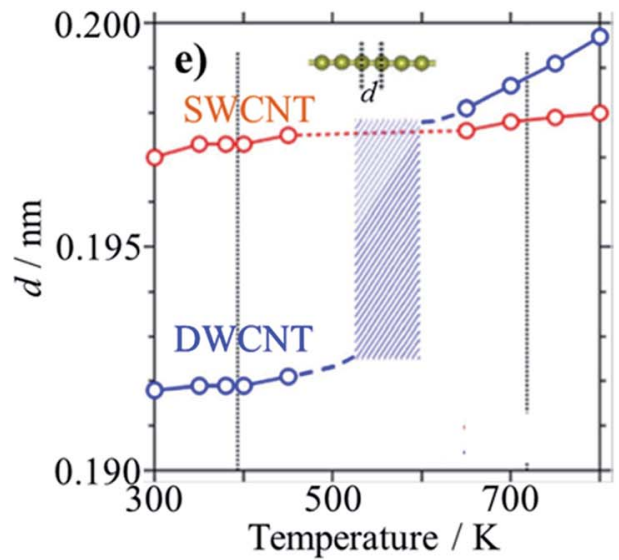

Fig. 6 Sulfur encapsulation into carbon nanotubes: TEM images of (a) two straight S-chains in SWCNT, (b) zigzag and (c) straight S-chains in DWCNTs, and temperature dependences of interatomic distance $d$ in SWCNT and DWCNT of (d) zigzag and (e) straight S-chains. Melting and boiling points for bulk sulfur ( 393 and $\sim 718 \mathrm{~K}$, respectively) are indicated by vertical lines for comparison. Adapted from ref. 30 with permission from Nature Publishing Group.
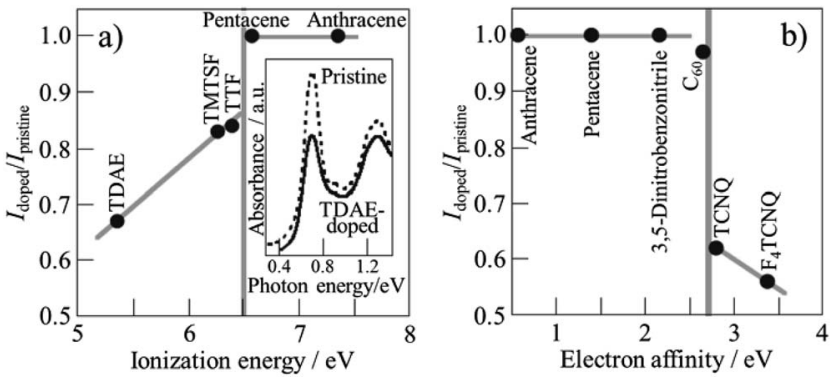

Fig. 7 Relations of absorption intensity ratio / doped $/ /_{\text {pristine }}$ to ionization energy and electron affinity of encapsulated molecules. Adapted from ref. 32 with permission from Nature Publishing Group.

batteries (SIBs) were performed in $1 \mathrm{M} \mathrm{LiClO}_{4} /(\mathrm{EC}+\mathrm{DEC})$ and $1 \mathrm{M} \mathrm{NaClO}_{4} / \mathrm{PC}$ electrolytes, respectively. LIB performances of AQ@SWCNT and PhQ@SWCNT were compared with the mechanical mixtures of $\mathrm{AQ}$ and $\mathrm{PhQ}$ with acetylene black (Fig. 8). These results demonstrated the reversible Li-ion storage of almost all quinone (AQ and $\mathrm{PhQ}$ ) molecules encapsulated in the SWCNTs. The capacity fading observed on the mechanical mixtures of quinones with acetylene black, which came from the dissolution of quinone molecules into the electrolyte, was markedly suppressed by the encapsulation. ${ }^{33}$ The effect of the tube diameter of SWCNT on the Li-ion storage was studied using two SWCNTs with different diameters of 1.5 and $2.5 \mathrm{~nm}$ (SWCNT-1.5 and -2.5, respectively), of which encapsulated PhQ amount was determined by thermogravimetric measurement to be 22 and $38 \mathrm{wt} \%$, respectively. ${ }^{34}$ The charge-discharge profiles and the reversible capacities of PhQ@SWCNTs at room temperature were quite similar for $\mathrm{Li}$ and $\mathrm{Na}$ ions, associating with two steps at 2.8 and $2.4 \mathrm{~V}$ for Li and those at 2.3 and $1.9 \mathrm{~V}$ for Na. Because the tube diameters of both SWCNTs are larger than the Li and $\mathrm{Na}$ ions and do not discriminate between these two ions. The reversible capacity of LIB using PhQ@SWCNT-1.5 was determined from the charge-discharge curves to be very close to the theoretical capacity of the PhQ molecule (258 $\mathrm{mA} \mathrm{h} \mathrm{g}{ }^{-1}$ ), but that using PhQ@SWCNT-2.5 was about a half of the theoretical one, suggesting that only a half of the encapsulated $\mathrm{PhQ}$ worked as electrode materials. This is explained by the strong interaction between SWCNTs and PhQ for narrower SWCNTs, forming a current flow path at the interface. The reversible LIB capacities of PhQ@SWCNT-1.5 and PhQ@SWCNT-2.5 at $0{ }^{\circ} \mathrm{C}$ were much smaller than those at room temperature probably due to kinetic problems, which was supported by the fact that the capacity measured at a very slow charging rate was as high as the theoretical one. Meanwhile, the
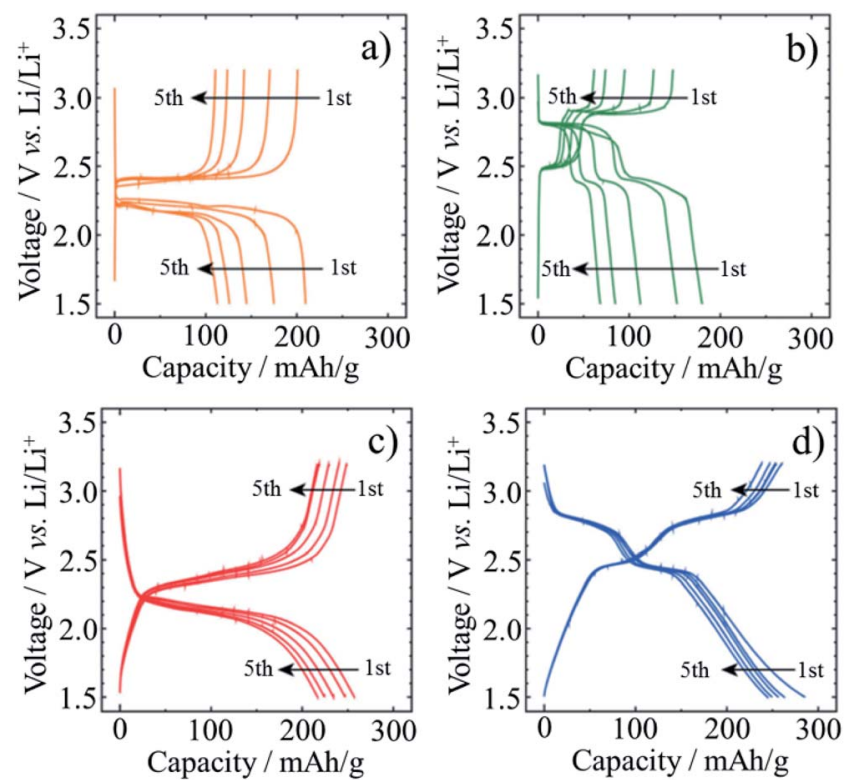

Fig. 8 Charge-discharge curves collected at a current density of $100 \mathrm{~mA} \mathrm{~g}^{-1}$ at room temperature: mechanical mixture of (a) AQ with acetylene black, (b) PhQ with acetylene black; quinone-encapsulated SWCNTs of (c) AQ@SWCNT and (d) PhQ@SWCNT. Adapted from ref. 33 with permission from the PCCP Owner Societies. 
capacities in SIBs at $0{ }^{\circ} \mathrm{C}$ for both electrodes slightly decreased in comparison with those at room temperature. Particularly, the reversible capacity of PhQ@SWCNT-2.5 at $0{ }^{\circ} \mathrm{C}$ was almost the same as that at room temperature, probably because of facile $\mathrm{Na}$ ion diffusion in SWCNT-2.5 even at a low temperature.

Encapsulation of $\beta$-carotene $\left(\mathrm{C}_{40} \mathrm{H}_{56}\right)$ which consists of eight isoprene units having beta-rings at both ends of the molecule, was shown to be very efficient to suppress its degradation under UV irradiation. ${ }^{35}$ The light degradation of $\beta$-carotene is induced by the reaction with radical species (e.g., singlet oxygen) and isomerization; however, a surrounding tube wall prevents $\beta$ carotene from such reactions inside the constraint space. Encapsulation of $\beta$-carotene, 9,10-dichloroanthracene, and coronene into SWCNTs resulted in the enhancement of LIB capacity. $^{36}$ Reversible capacity of coronene-encapsulated SWCNTs $(7.2 \mathrm{wt} \%$ ) was calculated to be $793 \mathrm{~mA}$ h per tube weight at $100 \mathrm{~mA} \mathrm{~g}^{-1}$ in $1 \mathrm{M} \mathrm{LiClO}_{4} /(\mathrm{EC}+\mathrm{DEC})$ electrolyte solution, whereas pristine SWCNTs exhibited reversible capacity of $316 \mathrm{~mA} \mathrm{~h} \mathrm{~g}{ }^{-1}$. Although both electrodes showed a high irreversible capacity, but the enhancement in the reversible capacity observed for organic molecule-encapsulated SWCNTs is attributed to the increase in the Li ion storage sites in the tubes.

Encapsulation of metallocene compounds into SWCNTs was studied on ferrocene ${ }^{37-40}$ and cobaltocene. ${ }^{41}$ Encapsulation of ferrocene, $\mathrm{FeCp}_{2}$, was performed by contacting purified SWCNTs with ferrocene vapor at $300{ }^{\circ} \mathrm{C}$ under vacuum, followed by washing with diethyl ether to remove ferrocene deposited on the surface of tubes. ${ }^{37}$ The resultant FeCp $\mathrm{F}_{2} @ S W C N T$ s retained the redox activity of $\mathrm{FeCp}_{2}$ itself in $0.1 \mathrm{M} \mathrm{Bu}_{4} \mathrm{NClO}_{4} /$ acetonitrile electrolyte. $\mathrm{FeCp}_{2}$ confined in SWCNTs could be converted to metallic Fe nanoparticles by heating up to $700{ }^{\circ} \mathrm{C}$ under vacuum to form Fe-confined SWCNTs (Fe@SWCNT). ${ }^{38}$ Fe nanoparticles formed in SWCNTs have two morphologies, as shown TEM images with illustrations in Fig. 9: individual Fe particles with the diameter of 0.5-0.7 nm, suggesting several Fe atom aggregation (Fig. 9a) and somewhat linear alignment of Fe particles (Fig. 9b). According to the TEM observation, the filling yield (ratio of filled SWCNTs to empty SWCNTs) was estimated to be more than $80 \%$. Encapsulation of $\mathrm{FeCp}_{2}$ into DWCNTs
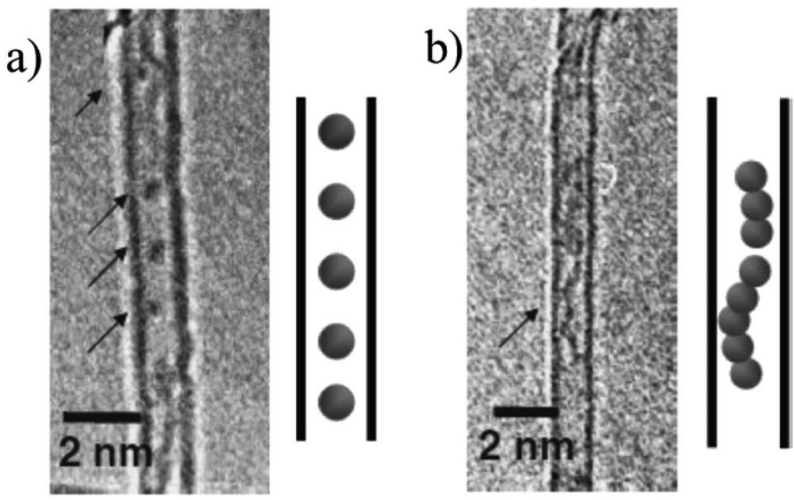

Fig. 9 TEM images and illustrations for two morphologies of $\mathrm{Fe}$ nanoparticles in FeaSWCNT. Adapted from ref. 38 with permission. Copyright (2006) the Japan Society of Applied Physics.
( $\left.\mathrm{FeCp}_{2} @ \mathrm{DWCNT}\right)$ resulted in marked change in electronic properties probably due to the charge transfer between $\mathrm{FeCp}_{2}$ molecules and DWCNTs, and Fe@DWCNT prepared from FeCp $_{2} @ D W C N T$ was unipolar n-type semiconductive. ${ }^{39}$ FeCp $p_{2} @ S W C N T$ could change to DWCNT by high temperature annealing. ${ }^{40}$ By annealing at $1150{ }^{\circ} \mathrm{C}$, all Fe atoms were released from the tube, while the annealing at $600{ }^{\circ} \mathrm{C}$ led to the formation of metastable iron carbide, which was supposed to act as a reactor by absorbing carbon atoms from one side of the tube and generating an inner tube to another side, forming DWCNT. Once the inner tubes had grown, the iron atoms diffused out of the tubes and aggregated into iron nanoparticles on the outside of DWCNTs, not in the channel. The intensity distributions of RBM Raman spectra for the inner-tube of $\mathrm{FeCp}_{2}$-derived DWCNTs were significantly different from those of $\mathrm{C}_{60}$-peapodderived DWCNTs. Bis(cyclopentadienyl) cobalt (cobaltocene, $\mathrm{CoCp}_{2}$ ) could be confined only in the SWCNTs with a tube diameter of $\sim 1 \mathrm{~nm}$ under vacuum at $100{ }^{\circ} \mathrm{C}$, whereas bis(ethylcyclopentadienyl) cobalt $\left(\mathrm{Co}(\mathrm{EtCp})_{2}\right)$ confinement was possible in a range of tube diameters greater than $\sim 1 \mathrm{~nm} .{ }^{41}$

\section{(e) Water molecules}

Encapsulation of water into strongly hydrophobic CNTs had not been expected, but computer simulations predicted certain possibility, ${ }^{42,43}$ even the formation of ice nanotubes inside of SWCNTs. ${ }^{44}$ Water molecules were experimentally shown to be adsorbed into de-capped SWCNTs at room temperature, and reversibly desorbed and re-adsorbed above room temperature. ${ }^{45,46}$ On water-confined SWCNTs, a structural change of adsorbed water at low temperatures was studied by using X-ray diffraction (XRD). ${ }^{45}$ XRD patterns of water-confined SWCNT at different temperatures are shown in Fig. 10a. A new diffraction peak appears at $Q=22 \mathrm{~nm}^{-1}$ at the temperature below $235 \mathrm{~K}$, and the intensity of the both peaks at $Q=22$ and $7.2 \mathrm{~nm}^{-1}$
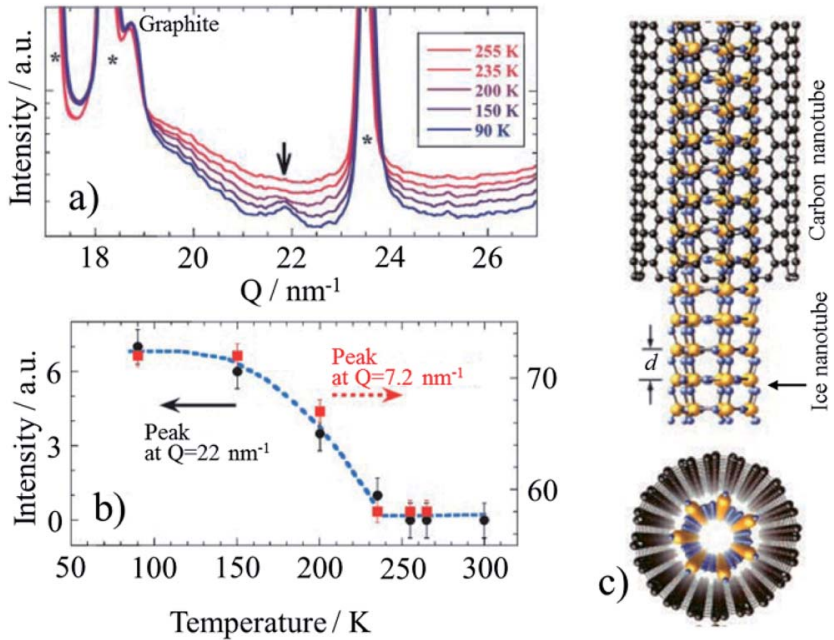

Fig. 10 Encapsulated water in SWCNT: (a) XRD profiles at different temperatures, (b) temperature dependence of the intensity of the peaks at 22 and $7.2 \mathrm{~nm}^{-1}$, and (c) a schematic illustration of the ice nanotube inside a SWCNT. Adapted from ref. 45 with permission. Copyright 2002 the Physical Society of Japan. 
increases with decreasing temperature (Fig. 10b), which is explained by solidification of water molecules as nanotube (ice nanotube), as shown schematically in Fig. 10c. By using SWCNTs having different tube diameter $(D)$ in the range of 1.17-2.40 $\mathrm{nm}$, temperature-diameter $(T-D)$ phase diagram of water confined into SWCNTs was determined on the bases of experimental results of XRD, ${ }^{1} \mathrm{H}$ and ${ }^{2} \mathrm{D}$ NMR, and electrical resistance measurements. ${ }^{46}$ In thin SWCNTs $(1.17<D<\sim 1.3$ $\mathrm{nm}$ ), water inside SWCNTs undergoes a liquid-solid-like transition and forms hollow ice nanotube structures at low temperature. For the large diameter SWCNTs $(\sim 1.6<D<2.40$ $\mathrm{nm}$ ), on the other hand, water cannot be retained inside the SWCNTs. In the intermediate diameter range $(D \sim 1.4 \mathrm{~nm})$, hollow ice nanotubes are formed at low temperature, while further increase in the water content leads to filled structures like ice nanotubes containing a one-dimensional water chain inside.

Loading and releasing processes of water molecules into SWCNTs were studied by X-ray diffraction analysis and hybrid reverse Monte Carlo simulations. ${ }^{47}$ Water loading was performed at vapor pressures of 3.1 and $3.8 \mathrm{kPa}$, corresponding to water filling rates of 50 and $100 \%$, respectively, and then water was released up to a vapor pressure of $2.3 \mathrm{kPa}$ (corresponding to water filling of $50 \%$ ). In the loading process, water molecules formed nanoclusters which were well stabilized in the channel of SWCNTs, while less stable water layers than water nanoclusters were formed in the releasing process.

\section{In carbon nanopores}

Nanopores, micropores, mesopores, and even macropores in carbon materials have been studied as adsorption sites for electrochemically active materials, such as $\mathrm{Li}$ for Li-ion batteries and different ions of aqueous and non-aqueous electrolytes for electrochemical capacitors, and also for various molecules and ions in gases and liquids, such as desalination of water, pollutant removals from wastes, etc. Recently, some of functional materials stored into these pores of carbon materials are experimentally demonstrated to show unique properties, as explained below, which are reasonably supposed to be caused by some constraints from nanopores of carbon materials. Functional materials can be encapsulated in these carbon nanopores, where functional materials are stably supported by constraint spaces and have a large contact area with the conductive carbon surface, which endows the functional materials with different characteristics from those in a bulk state.

\section{(a) Electrochemically-active organics}

Confinement of polyaniline (PANI) into the micropores of activated carbon (AC) was shown to be effective to enhance the volumetric capacitance of electrochemical capacitors while retaining high power density, which is characteristic of electric double-layer capacitors. ${ }^{\mathbf{4 8 4} 9}$ Aniline (ANI) was adsorbed at $25{ }^{\circ} \mathrm{C}$ into a commercially available $\mathrm{AC}$, followed by electrochemical polymerization in an aqueous $1 \mathrm{M} \mathrm{H}_{2} \mathrm{SO}_{4}$ electrolyte. ${ }^{48}$ The AC employed was $\mathrm{KOH}$-activated and microporous with a Brunauer-Emmett-Teller specific surface area $\left(S_{\mathrm{BET}}\right)$ of $2070 \mathrm{~m}^{2}$ $\mathrm{g}^{-1}$, of which maximum adsorption capacity of ANI was $48 \mathrm{wt} \%$. As shown the cyclic voltammograms in an aqueous $1 \mathrm{M} \mathrm{H}_{2} \mathrm{SO}_{4}$ electrolyte in Fig. 11a, the PANI-confined AC composites exhibit distinct anodic and cathodic peaks at $0.4-0.6 \mathrm{~V}$ due to the redox reaction of PANI, in addition to a rectangular voltammogram of the pristine AC, typical electric double-layer behavior. Fig. 11b shows the gravimetric capacitances measured by galvanostatic charge/discharge as a function of current density (rate performance). As shown in the figure, the confinement of PANI into the micropores of AC up to about $30 \mathrm{wt} \%$ is effective to enhance the gravimetric capacitance by pseudocapacitance of PANI. The synthesis of PANI in the micropores is not accompanied by the volumetric expansion of the AC particles. Therefore, the capacitance per unit mass of AC is proportionally correlated with the volumetric capacitance for the PANI-confined AC composites. As shown in Fig. 11c, their volumetric capacitances are enhanced with increasing amount of pseudocapacitive PANI. Of note in the figure is that the PANI-confined AC composites exhibit higher rate performance than the $\mathrm{AC}$, i.e., the pseudocapacitance of PANI showed superior rate performance over the double-layer capacitance. This is realized by utilizing constraint spaces of AC, where PANI has a large contact area with conductive carbon surfaces. In addition, the pore confinement was found to be effective for improving the cycle lifetimes by absorbing the swelling of PANI during the charging process.

Polypyrene (PPY) and PANI were confined into not only micropores but also mesopores of a commercial AC (MSC30), which had a large $S_{\mathrm{BET}}$ of $3160 \mathrm{~m}^{2} \mathrm{~g}^{-1}$, micropore volume $\left(V_{\text {micro }}\right)$ of $0.99 \mathrm{~cm}^{3} \mathrm{~g}^{-1}$, and mesopore volume $\left(V_{\text {meso }}\right)$ of 0.60 $\mathrm{cm}^{3} \mathrm{~g}^{-1}$. The vapor of pyrene (PY) and ANI were adsorbed in the $\mathrm{AC}$ at 150 and $25{ }^{\circ} \mathrm{C}$, respectively, followed by electrochemical polymerization in an aqueous $1 \mathrm{M} \mathrm{H}_{2} \mathrm{SO}_{4} \cdot{ }^{49}$ The adsorption saturations of PY and ANI occurred at 60.2 and $62.4 \mathrm{wt} \%$, respectively, for this AC. The capacitive performances are shown on the ACs with different amounts of PPY in Fig. 12. Anodic and cathodic peaks at $0.3-0.4 \mathrm{~V}$ due to the redox reaction of PPY confined into the AC pores are clearly observed in their cyclic voltammograms (Fig. 12a), as observed on the PANI-confined ACs (Fig. 11a), which gave the pseudocapacitance to the capacitors. By the confinement of 30-50 wt\% PPY, gravimetric and volumetric capacitances of the cells are markedly enhanced, as shown in Fig. 12c and d. The maximum volumetric capacitance for the PPY-confined ACs and the PANIconfined ACs reached 314 and $299 \mathrm{~F} \mathrm{~cm}^{-3}$, respectively. Although the increment in the observed volumetric capacitances are reasonably supposed to be due to the pseudocapacitance of PPY, the rate performances of the cells are also improved, as shown in Fig. 12b, suggesting that the redox reaction of PPY occur more rapidly than the double-layer formation inside the nanopores. These results revealed that a large contact area between conductive polymers and carbon surfaces enables compatibility of high volumetric energy and high power densities for electrochemical capacitor electrodes. 

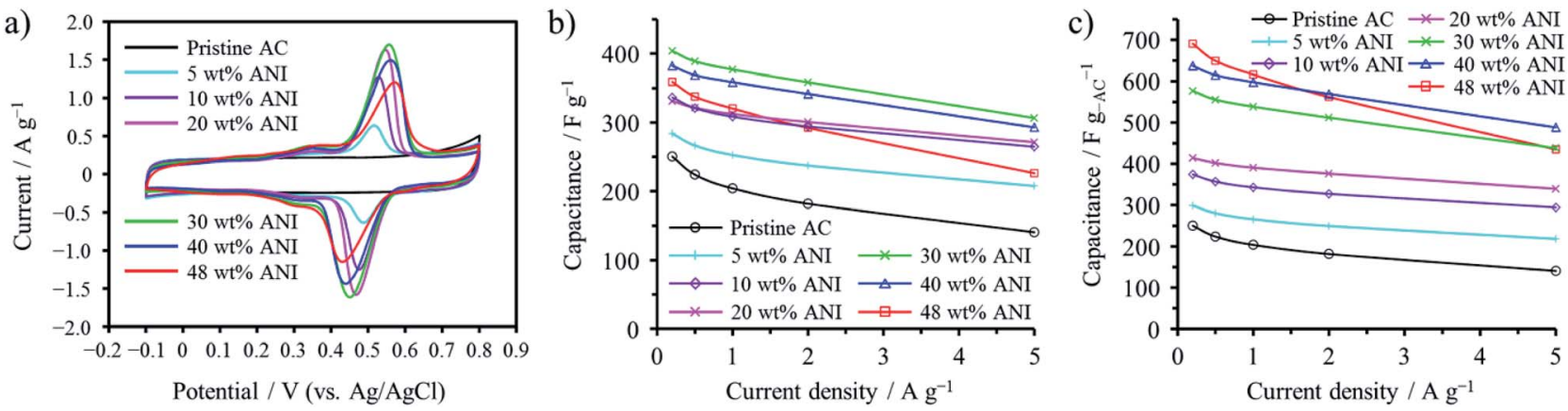

Fig. 11 Electrochemical capacitor behaviors of PANI-confined ACs: (a) cyclic voltammograms collected at $1 \mathrm{mV} \mathrm{s}^{-1}$, (b) gravimetric and (c) volumetric capacitance dependences on the current density. Adapted from ref. 48 with permission from the Royal Society of Chemistry.

2,5-Dichloro-1,4-benzoquinone (DCBQ) was confined into the pores of Ketjenblack (KB; $S_{\mathrm{BET}}: 1340 \mathrm{~m}^{2} \mathrm{~g}^{-1}, V_{\text {micro }}: 0.48 \mathrm{~cm}^{3}$ $\mathrm{g}^{-1}, V_{\text {meso }}: 1.24 \mathrm{~cm}^{3} \mathrm{~g}^{-1}$ ) at $100{ }^{\circ} \mathrm{C}$ (a little higher than the sublimation temperature of DCBQ, $\left.92^{\circ} \mathrm{C}\right) \cdot{ }^{50}$ The weight content of DCBQ in the DCBQ-confined KB was tuned to be 5, 10, 20, and $40 \mathrm{wt} \%$. In addition, $\mathrm{KB}$ was saturated using excess amount of DCBQ, with the saturation amount reaching $60.1 \mathrm{wt} \% \mathrm{~N}_{2}$ adsorption-desorption curves shown in Fig. 13a suggest that DCBQ was adsorbed into both micropores and mesopores, $V_{\text {micro }}$ and $V_{\text {meso }}$ being reduced to 0.17 and $0.71 \mathrm{~cm}^{3} \mathrm{~g}^{-1}$, respectively, with a $40 \mathrm{wt} \%$ DCBQ content; and giving $V_{\text {micro }}$ of $0.03 \mathrm{~cm}^{3} \mathrm{~g}^{-1}$ and $V_{\text {meso }}$ of $0.15 \mathrm{~cm}^{3} \mathrm{~g}^{-1}$ upon saturation. The DCBQ-confined KBs exhibit clearly the presence of redox reaction of DCBQ by a plateau in galvanostatic charge-discharge curves in an aqueous $1 \mathrm{M} \mathrm{H}_{2} \mathrm{SO}_{4}$ electrolyte, as shown in Fig. 13b, although the pristine KB shows almost linear characteristics (i.e., electric double-layer behavior). In Fig. 13c and d, gravimetric and volumetric capacitances are plotted against current density, revealing that excellent rate performance of the pristine KB is retained even in DCBQ-confined KBs. DCBQ has a)

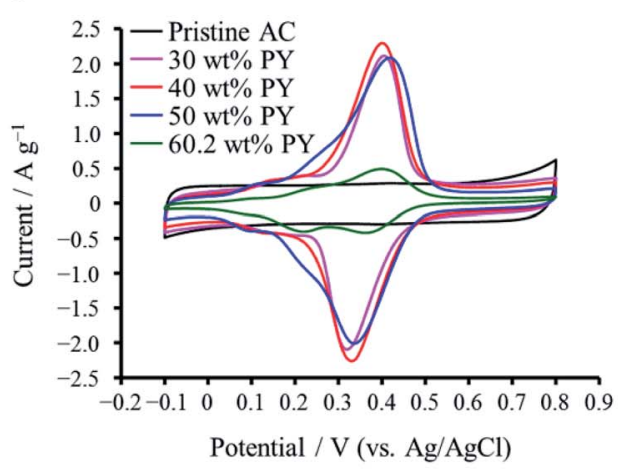

c)

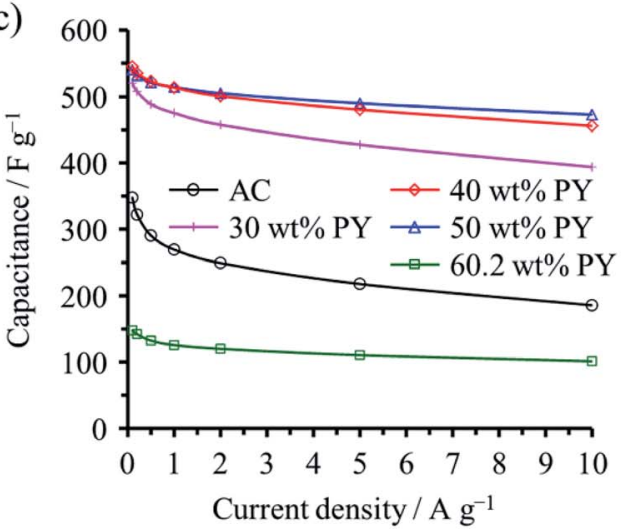

b)

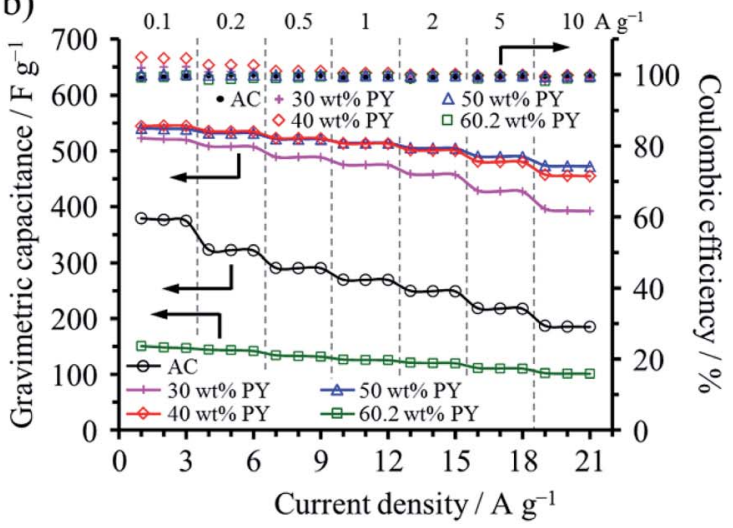

d)

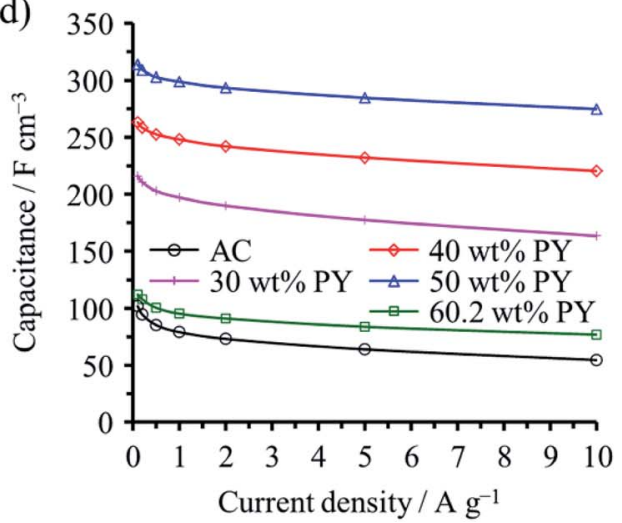

Fig. 12 Electrochemical capacitor behaviors of PPY-confined ACs: (a) cyclic voltammograms with $1 \mathrm{mV} \mathrm{s}^{-1}$ rate, (b) dependences of gravimetric capacitance and coulombic efficiency on the cycle number, (c) rate performances of the gravimetric capacitance, and (d) those of the volumetric capacitance. Adapted from ref. 49 with permission from the Royal Society of Chemistry. 
a)

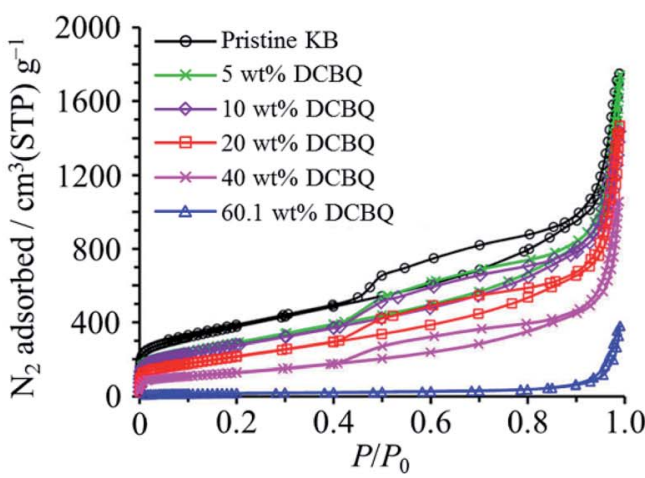

c)

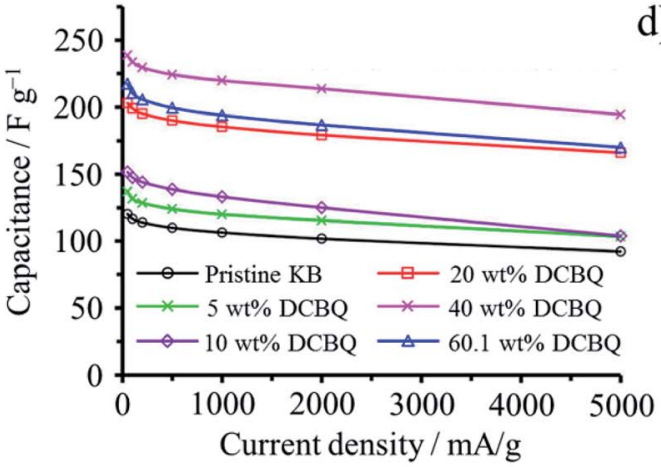

b)

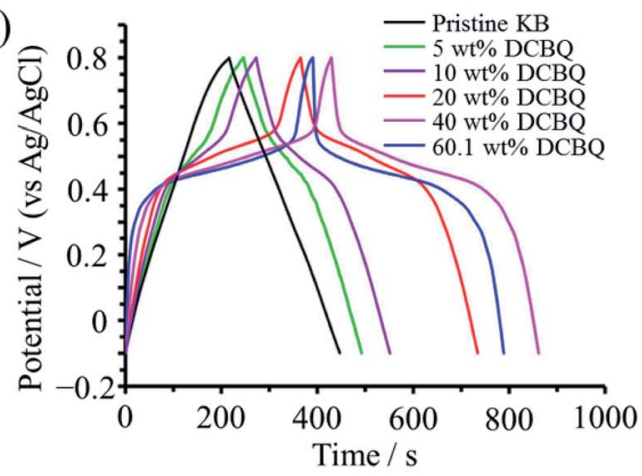

d)

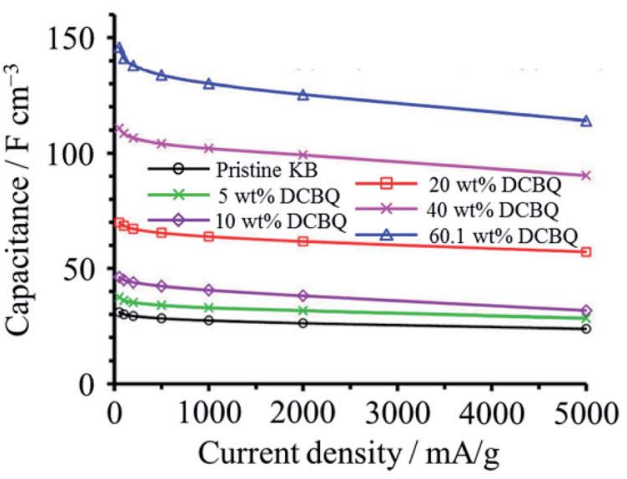

Fig. 13 DBCQ-confined Ketjenblack: (a) $\mathrm{N}_{2}$ adsorption-desorption curves at $77 \mathrm{~K}$, (b) galvanostatic charge-discharge curves in $1 \mathrm{M} \mathrm{H}_{2} \mathrm{SO}_{4}$ electrolyte measured at a current density of $50 \mathrm{~mA} \mathrm{~g}^{-1}$, (c) rate performances of the gravimetric capacitance, and (d) those of the volumetric capacitance. Adapted with permission from ref. 50. Copyright 2016 American Chemical Society.

poor electrical conductivity by itself, like most organic compounds, but a large contact area between finely dispersed DCBQ in the pores of $\mathrm{KB}$ and conductive carbon surfaces enables fast charge transfer at the interface. Gravimetric capacitance reaches a maximum with a DCBQ content of $40 \mathrm{wt} \%$, but the KB saturated with DCBQ gives a maximum volumetric capacitance. The resulting capacitor was characterized by high capacitances, particularly high volumetric capacitances as 4.7 times higher than that of the pristine $\mathrm{KB}$, along with high rate capability up to $5 \mathrm{~A} \mathrm{~g}^{-1}$ and excellent cycle lifetimes up to 10000 cycles.

One of 2,2,6,6-tetramethylpiperidine- $N$-oxyl (TEMPO) derivatives, 4-hydroxy-TEMPO benzoate (HTB), was confined into the nanopores of the AC (MSC30; $S_{\mathrm{BET}}: 3160 \mathrm{~m}^{2} \mathrm{~g}^{-1}, V_{\text {micro }}: 0.99 \mathrm{~cm}^{3}$ $\mathrm{g}^{-1}, V_{\text {meso }}: 0.60 \mathrm{~cm}^{3} \mathrm{~g}^{-1}$ ) through its vapor at $130{ }^{\circ} \mathrm{C}$, and the capacitive performances of the resultant HTB-confined ACs with different HTB contents (20-50 wt\%) were studied in an aqueous $1 \mathrm{M} \mathrm{H}_{2} \mathrm{SO}_{4}$ electrolyte. ${ }^{51} \mathrm{~A}$ marked reduction in pore parameters with increasing adsorbed amount of HTB suggested the confinement of HTB molecules into nanopores of AC, with the $S_{\mathrm{BET}}, V_{\text {micro }}$, and $V_{\text {meso }}$ reducing to $250 \mathrm{~m}^{2} \mathrm{~g}^{-1}, 0.07 \mathrm{~cm}^{3} \mathrm{~g}^{-1}$, and $0.05 \mathrm{~cm}^{3} \mathrm{~g}^{-1}$, respectively, by adsorption of HTB up to $50 \mathrm{wt} \%$. Anodic and cathodic peaks derived from the redox reaction of HTB were clearly observed at around $0.7 \mathrm{~V}$. The redox potential of HTB is higher than those of many organic redox compounds and conductive polymers, which is advantageous to enhance the energy density of the HTB-confined ACs. The composite with $30 \mathrm{wt} \% \mathrm{HTB}$ exhibited higher volumetric energy and power densities than the pristine $\mathrm{AC}: 39.5 \mathrm{~W} \mathrm{~h} \mathrm{~kg}^{-1}$ at $16.5 \mathrm{~W} \mathrm{~kg}^{-1}$ and $14.1 \mathrm{~W} \mathrm{~h} \mathrm{~kg}^{-1}$ at $8.2 \mathrm{~kW} \mathrm{~kg}^{-1}$ for the composite in contrast to $18.0 \mathrm{~W} \mathrm{~h} \mathrm{~kg}^{-1}$ at $16.5 \mathrm{~W} \mathrm{~kg}^{-1}$ and $1.1 \mathrm{~W} \mathrm{~h} \mathrm{~kg}^{-1}$ at $8.2 \mathrm{~kW} \mathrm{~kg}^{-1}$ for the pristine AC. Volumetric comparison shows a further enhancement in the volumetric energy and power densities of the composite with $30 \mathrm{wt} \%$ HTB: a 3.1 times enhancement $\left(16.5 \mathrm{~W} \mathrm{~h} \mathrm{~L}^{-1}\right)$ at $6.9 \mathrm{~W} \mathrm{~L}^{-1}$ and a 18 time enhancement $\left(5.9 \mathrm{~W} \mathrm{~h} \mathrm{~L}^{-1}\right)$ at $3.5 \mathrm{~kW} \mathrm{~L}^{-1}$. The high redox potential of HTB and a large contact area between the conductive carbon surface and HTB realized compatibility between the enhancements in both volumetric energy and power densities. The confinement of HTB molecules into the nanopores of AC was effective to prevent dissolution of HTB in an aqueous electrolyte with the aid of a hydrophobic group in HTB and to improve markedly the contact of HTB with a conductive carbon surface, which was supposed to allow for fast redox reactions of HTB, in addition to fine dispersion of minute aggregates of HTB molecules.

\section{(b) Inorganics}

$\mathrm{MnO}_{2}$ nanocrystals confined into nanopores of porous carbon nanofibers (CNFs) delivered high electrochemical capacitance in $1 \mathrm{M} \mathrm{Na}_{2} \mathrm{SO}_{4}$ aqueous electrolyte, the electrodes of the $\mathrm{MnO}_{2} /$ CNF composite giving the capacitance of $1282 \mathrm{~F} \mathrm{~g}^{-1}$ with the current density of $0.2 \mathrm{~A} \mathrm{~g}^{-1} .^{52}$ Porous CNFs were synthesized from the mixture of polyimide with polyvinylpyrrolidone (PVP) via electrospinning, followed by carbonization. In order to confine $\mathrm{MnO}_{2}$ nanocrystals preferentially in the nanopores, the 
porous CNFs had to be immersed into the $\mathrm{KMnO}_{4}$ aqueous solution with the concentration of less than $0.024 \mathrm{~g} \mathrm{~L}^{-1}$, while higher concentration of $\mathrm{KMnO}_{4}$ solution resulted in $\mathrm{MnO}_{2}$ deposition mostly on the external surface of the CNF. The $\mathrm{MnO}_{2}$ nanocrystals in the inner part of CNF were grown along with (200) crystal faces under nanopore constraint and therefore had ultrathin structures, whereas the nanocrystals in the external part of CNF were grown along with (211) crystal faces (Fig. 14). The former nanocrystals enable the shortened diffusion path for electrolyte and a large active surface area. A symmetrical capacitor of the $\mathrm{MnO}_{2} / \mathrm{CNF}$ composite electrode prepared in the optimized condition could deliver the energy density of $36 \mathrm{~W} \mathrm{~h} \mathrm{~kg}{ }^{-1}$ with a power density of $39 \mathrm{~W} \mathrm{~kg}^{-1}$ and maintained $7.5 \mathrm{~W} \mathrm{~h} \mathrm{~kg}^{-1}$ at $10.3 \mathrm{~kW} \mathrm{~kg}^{-1}$.

The electrochemical cell consisting of the same $\mathrm{KOH}^{-}$ activated porous carbon ( $S_{\mathrm{BET}}$ of $2181 \mathrm{~m}^{2} \mathrm{~g}^{-1}$ ) worked as a hybrid cell, battery-type behavior at the positive electrode and capacitor-type one at the negative electrode in an aqueous electrolyte containing $2 \mathrm{M} \mathrm{MnSO}_{4}$ and $0.5 \mathrm{M} \mathrm{KI}$, although it worked as a capacitor in $2 \mathrm{M} \mathrm{MnSO}_{4}$ electrolyte. ${ }^{53}$ This hybrid behavior in alkali metal iodide-based aqueous electrolytes was concluded to be owing to the confinement of polyiodides in the porosity of the positive carbon electrode creating a so-called carbon/iodide interface, ${ }^{54}$ the confinement of polyiodides being confirmed by the measurement of Raman spectra. ${ }^{53}$ Effectiveness of the confinement of electrochemically-active materials was reported on $\mathrm{Sn}^{55,56}$ and Ge..$^{57,58}$

$\mathrm{BaTiO}_{3}$ rod-like crystals were synthesized in the nanopores of single-wall carbon nanohorns (SWCNHs). ${ }^{59} \mathrm{TiO}_{2}$ was firstly encapsulated into the nanopores of SWCNHs by impregnating an aqueous $\mathrm{TiCl}_{4}$ solution and following annealing at $373 \mathrm{~K}$. The resulting $\mathrm{TiO}_{2}$ was reacted with $\mathrm{Ba}\left(\mathrm{OCH}_{2} \mathrm{CH}_{3}\right)_{2}$ at $400 \mathrm{~K}$ in an autoclave of $\mathrm{N}_{2}$ atmosphere, and the resultant $\mathrm{BaTiO}_{3}$ rods having high aspect ratio $(2-4 \mathrm{~nm}$ in diameter and $40-60 \mathrm{~nm}$

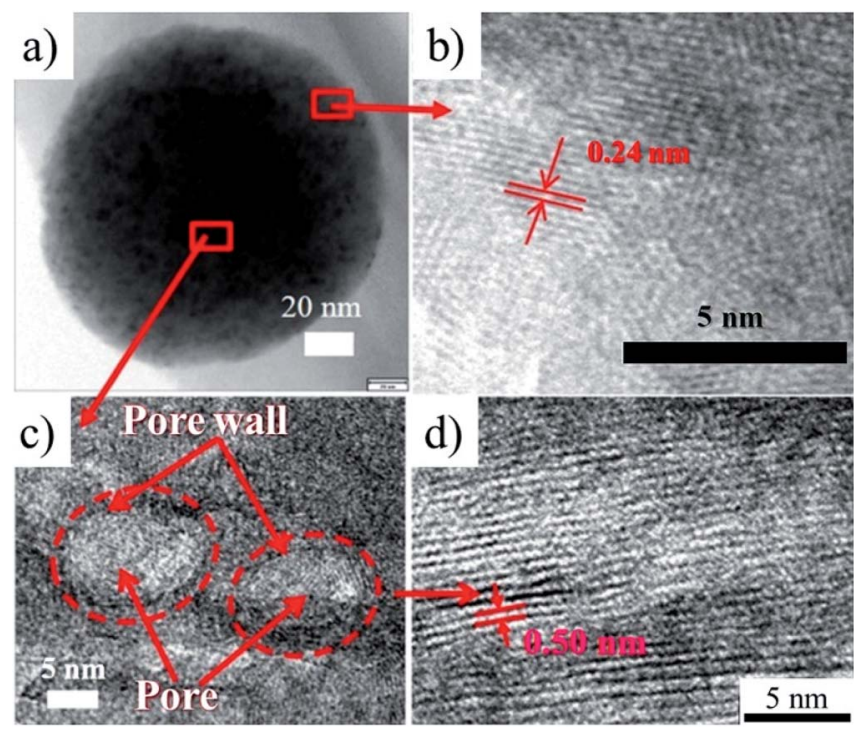

Fig. 14 TEM images of $\mathrm{MnO}_{2}$ nanocrystals confined in the pore (c and d) and deposited on the surface (b) of the porous carbon nanofiber (a) Adapted from ref. 52 with permission from Nature Publishing Group. length) were obtained. By impregnation of SWCNHs in methanol/2-methoxyethanol mixed solution of $\mathrm{Ba}\left(\mathrm{OCH}_{2} \mathrm{CH}_{3}\right)_{2}$ and $\mathrm{Ti}\left(\mathrm{OCH}\left(\mathrm{CH}_{3}\right)_{2}\right)_{4}$ and subsequent annealing at $400 \mathrm{~K}$ in an autoclave, spherical $\mathrm{BaTiO}_{3}$ particles with the diameters of 2$4 \mathrm{~nm}$ were synthesized in the nanopores of SWCNHs, whereas the $\mathrm{BaTiO}_{3}$ particles with the diameters of $20-40 \mathrm{~nm}$ were synthesized via the same process without using SWCNHs.

\section{(c) Platinum}

Loading of subnanometer-sized Pt clusters $\left(\mathrm{Pt}_{4-5}\right)$ onto carbon materials was shown to be possible by confining a Pt precursor into their micropores. ${ }^{60}$ An organometallic precursor, (COD) $\mathrm{PtMe}_{2}$ (COD: 1,5-cyclooctadiene) was selected as a Pt precursor, which was strongly adsorbed in the micropores of carbon substrates by a wet impregnation technique and easily reduced by a thermal treatment. Ketjenblack (KB; $S_{\text {BET }}: 1290 \mathrm{~m}^{2} \mathrm{~g}^{-1}$, $V_{\text {micro }}: 0.46 \mathrm{~cm}^{3} \mathrm{~g}^{-1}$ ) and zeolite-templated microporous carbon (ZTC; $S_{\mathrm{BET}}: 3680 \mathrm{~m}^{2} \mathrm{~g}^{-1}, V_{\text {micro }}: 1.55 \mathrm{~cm}^{3} \mathrm{~g}^{-1}$ ) were employed as carbon substrates. The carbon substrate was refluxed in dehydrated acetonitrile solution of the Pt precursor under $\mathrm{N}_{2}$ atmosphere to adsorb the Pt precursor, followed by filtering, washing with acetonitrile, and then washing with diethyl ether to remove the precipitated Pt precursor on the outer surface of the carbon substrate particles. The Pt precursor was reduced to metallic Pt by heat treatment at $300{ }^{\circ} \mathrm{C}$. The contents of the Ptprecursor after wet impregnation and that of metallic Pt after the heat treatment were 6.6 and $3.96 \mathrm{wt} \%$, respectively for $\mathrm{KB}$, and 20.0 and $12.8 \mathrm{wt} \%$, respectively for ZTC. The ratio of the Pt content for KB to that of ZTC substrate was roughly 1/3, being almost the same as the ratio of $V_{\text {micro }}$ in the two substrates. The TEM images after the Pt-loading on KB and ZTC were shown in Fig. 15a and b, respectively. Even after impregnation and heating at $300{ }^{\circ} \mathrm{C}$, no crystalline phase of the Pt-precursor nor the metallic Pt was detected by XRD, and the sizes of the Pt particles were supposed to be less than 1-2 nm from TEM images. X-ray absorption spectroscopy (XAS) analysis revealed that $\mathrm{Pt}_{4-5}$ subnano-sized clusters were supported on $\mathrm{KB}$ and ZTC, and their Pt-Pt bond length were substantially contracted $(\sim 2.8 \%)$ in comparison with that of bulk Pt because of the substantial surface tension in the unsaturated coordination environment of the $\mathrm{Pt}$ atoms. The adsorption of the Pt-

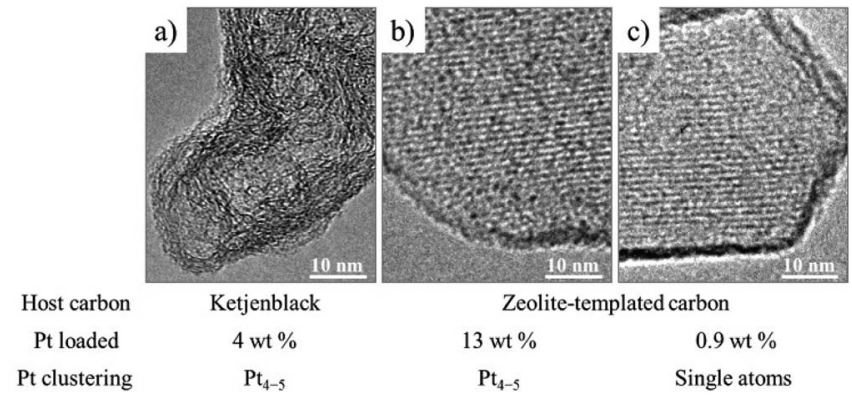

Fig. 15 TEM images of Pt-loaded carbon materials: (a) Ketjenblack and (b and c) ZTC. Adapted with permission from ref. 60. Copyright 2017 American Chemical Society. 
precursor into micropores was supposed to be crucial to prevent agglomeration and/or sintering of Pt nanoparticles. On ZTC with a low Pt content, Pt was dispersed as a single atom, as shown in Fig. 15c. The dispersion of Pt single atoms required the strong interaction between Pt atoms and oxygen-containing functional groups in ZTC, which was supported by the results of XAS analysis.

Pt nanoparticles were loaded on an $\mathrm{Ar}^{+}$-ion irradiated glassy carbon plate by radio-frequency magnetron sputtering with plasma output of $20 \mathrm{~W}$ for $60 \mathrm{~s}$ at fluences up to $1.0 \times 10^{16}$ ions per $\mathrm{cm}^{2}{ }^{61} \mathrm{Pt}$ was supposed to be confined at the defects created by the irradiation of $380 \mathrm{keV} \mathrm{Ar}^{+}$as minute clusters with an average size of about $5 \mathrm{~nm}$. A strong interfacial interaction between Pt nanoparticles and the glassy carbon substrate was estimated from its Pt $4 \mathrm{f}_{7 / 2}$ and C 1s XPS spectra.

\section{(d) Graphitic carbon nitride}

Graphitic carbon nitride $\left(\mathrm{g}-\mathrm{C}_{3} \mathrm{~N}_{4}\right)$, which has high activity of oxygen reduction reaction (ORR), ${ }^{62}$ was confined into a mesoporous carbon, CMK-3, by impregnating cyanamide as a precursor, followed by calcination at $5500^{\circ} \mathrm{C}$ in Ar atmosphere. The resulting g- $_{3} \mathrm{~N}_{4} @ \mathrm{CMK}-3$ delivered activity comparable to a commercially available $\mathrm{Pt} / \mathrm{C}$ catalyst, while showed much improved tolerance for methanol contamination. ${ }^{63}$ As shown in Fig. 16, the characteristic mesoporous structure due to the ordered nanochannels of the host CMK-3 was kept even after confinement of g- $\mathrm{C}_{3} \mathrm{~N}_{4}$, with the g- $\mathrm{C}_{3} \mathrm{~N}_{4}$ content being $27.1 \mathrm{wt} \%$. Before the preparation of the composite, the host CMK-3 rods were treated with $\mathrm{HNO}_{3}$ to make the host surfaces hydrophilic. The ORR activity of the composite was much better than the bulk g- $\mathrm{C}_{3} \mathrm{~N}_{4}$ and the mechanical mixture of $\mathrm{g}-\mathrm{C}_{3} \mathrm{~N}_{4}$ with CMK-3. Since the CMK-3 has a high surface area and high electrical conductivity, CMK-3 not only serves as a support for the g- $\mathrm{C}_{3} \mathrm{~N}_{4}$ but also confines the $\mathrm{g}_{-} \mathrm{C}_{3} \mathrm{~N}_{4}$ catalyst inside its nanospaces, which facilitates the electron transport necessary for an efficient $4 \mathrm{e}^{-}$ORR pathway.

In lithium-sulfur (Li-S) batteries, anchoring lithium polysulfides $\left(\mathrm{Li}_{2} \mathrm{~S}_{x}\right)$ in the cathode materials is strongly demanded to inhibit their shuttling between electrodes during charge/ discharge cycles, which would lead to the dissolution of $\mathrm{Li}_{2} \mathrm{~S}_{x}$ $(4 \leq x \leq 8)$ into commonly used electrolytes, resulting in the short cycle lifetimes of the electrodes and lithium anode contamination. Codoping of $\mathrm{N}$ and $\mathrm{S}$ into mesoporous carbons was demonstrated to be effective to enhance the affinity for $\mathrm{Li}_{2} \mathrm{~S}_{x}$, preventing their dissolution into an electrolyte. ${ }^{64}$ The
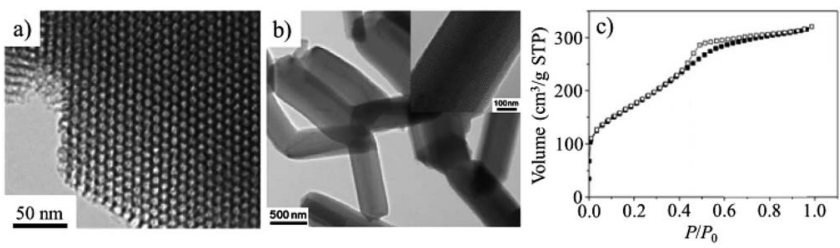

Fig. 16 g- $\mathrm{C}_{3} \mathrm{~N}_{4} / \mathrm{CMK}-3$ composite: (a) TEM image, (b) SEM image, and (c) $\mathrm{N}_{2}$ adsorption/desorption isotherm. Adapted with permission from ref. 63. Copyright 2011 American Chemical Society. composite of conductive vanadium nitride (VN) with reduced graphene oxide (rGO) was also reported to deliver good rate and cycling performances, with the initial capacity being $1471 \mathrm{~mA} \mathrm{~h} \mathrm{~g}^{-1}$ with only $15 \%$ capacity reduction after 100 cycles at $0.2 \mathrm{C}$ rate..$^{65}$ The conductive and porous structure of the $\mathrm{VN} /$ rGO composite facilitates the electron transportation and $\mathrm{Li}$ ion diffusion. In addition, since the VN has not only high electrical conductivity but also catalytic activity, it shows an anchor effect on the polysulfides and accelerates their redox reactions. $\mathrm{g}-\mathrm{C}_{3} \mathrm{~N}_{4}$ nanodots with the sizes less than $5 \mathrm{~nm}$ were confined into a MOF-derived N,S-codoped hollow porous carbon shell, and the resulting composite demonstrated excellent performances in Li-S batteries as cathode. ${ }^{66}$ As shown in Fig. 17, the composite exhibits much higher capacity and much better rate and cycle performances than neat g- $\mathrm{C}_{3} \mathrm{~N}_{4}$ and the pristine porous carbon. The composite delivered $1447 \mathrm{~mA} \mathrm{~h} \mathrm{~g}^{-1}$ at $0.2 \mathrm{C}$ rate and $387 \mathrm{~mA} \mathrm{~h} \mathrm{~g}^{-1}$ at $5 \mathrm{C}$, with excellent cycling stability as only $0.048 \%$ capacity reduction at $1.0 \mathrm{C}$ after 500 cycles. The synergetic effect of hollow carbon structure, N,Scodoping, and encapsulation of $\mathrm{g}-\mathrm{C}_{3} \mathrm{~N}_{4}$ facilitates the electron transfer and endows the composite with strong adsorption affinity for polysulfides to suppress the polysulfide shuttling.

\section{(e) Methane hydrate}

Water molecules confined into nanopores of AC could adsorb methane under the pressure above $3.5 \mathrm{MPa}$ at $2{ }^{\circ} \mathrm{C}$ to form methane hydrate. ${ }^{67}$ The AC used was prepared from mesophasepitch at $450{ }^{\circ} \mathrm{C}$, followed by the activation using $\mathrm{KOH}$ at $800{ }^{\circ} \mathrm{C}$. The AC had a $S_{\text {BET }}$ of $3670 \mathrm{~m}^{2} \mathrm{~g}^{-1}, V_{\text {micro }}$ of 1.20 , and $V_{\text {meso }}$ of $1.24 \mathrm{~cm}^{3} \mathrm{~g}^{-1}$. In Fig. 18, methane adsorption/desorption isotherms at $2{ }^{\circ} \mathrm{C}$ are shown for the AC with different preadsorbed water contents $\left(R_{\mathrm{w}}\right.$ in $\left.\mathrm{g} \mathrm{g}^{-1}\right)$. Their methane adsorption capacity depended strongly on $R_{\mathrm{w}}$ and was much larger than the dry AC $\left(R_{\mathrm{w}}=0\right)$. At low methane pressure, the wet ACs show the lower adsorption capacity than the dry one, probably due to pore blocking by pre-adsorbed water. Above $3 \mathrm{MPa}$ pressure, however, the adsorption capacity of methane shows sigmoidal increases, particularly for the AC with the high $R_{\mathrm{w}}$ value. The formation of methane hydrate was proved by inelastic neutron scattering and synchrotron X-ray powder diffraction. This condition of methane hydrate formation (3.5 $\mathrm{MPa}$ and $2{ }^{\circ} \mathrm{C}$ ) in nanopores of the $\mathrm{AC}$ is much milder, and
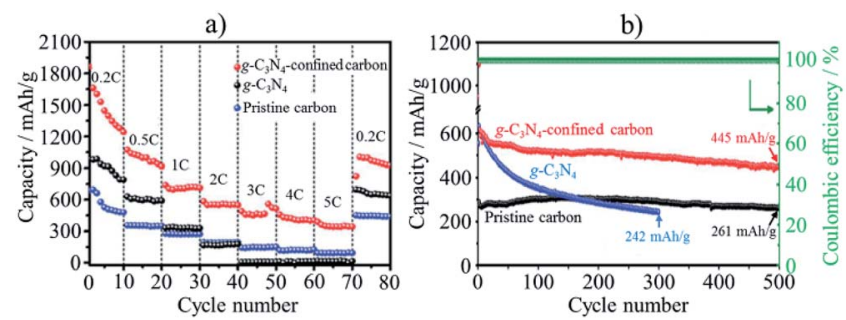

Fig. $17 \mathrm{Li}-\mathrm{S}$ battery performances of $\mathrm{g}-\mathrm{C}_{3} \mathrm{~N}_{4}$-confined porous carbon in comparison with $\mathrm{g}-\mathrm{C}_{3} \mathrm{~N}_{4}$ and pristine porous carbon: (a) rate performances and (b) cycle performances at $1 \mathrm{C}$ rate. Adapted from ref. 66 with permission from the Royal Society of Chemistry. 

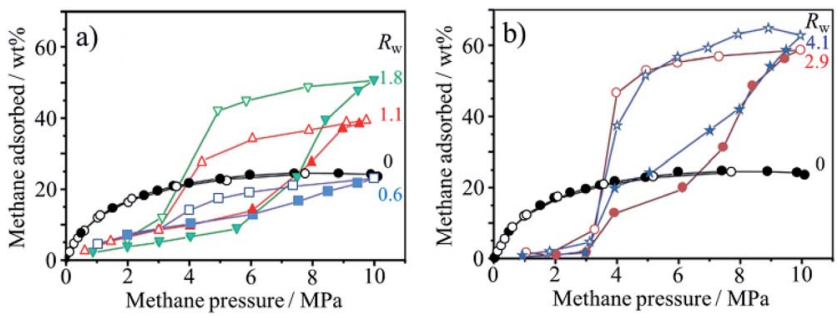

Fig. 18 Methane adsorption/desorption isotherms of the activated carbon having different pre-absorbed water content $R_{\mathrm{w}}$. Adapted from ref. 67 with permission from Nature Publishing Group.

hydration proceeds much faster (finishing within minutes) than the occurrence of methane hydrate in nature (more than $6 \mathrm{MPa}$ and slightly below room temperature). The ACs with high water contents, $R_{\mathrm{w}}$ of 2.9 and 4.1 (over-saturated), give two-step adsorption isotherms with pronounced hysteresis (Fig. 18b), suggesting that adsorption/desorption mechanisms for methane for wet ACs are different in the dry one, and the methane hydrate formed in carbon nanopores is stable.

\section{Carbon coating}

Carbon coating has been performed on different functional materials to improve their performances, such as a marked improvement in photocatalytic activity of anatase-type $\mathrm{TiO}_{2}$, a performance enhancement of electrode materials for LIBs and electrochemical capacitors, as reviewed before. ${ }^{68}$ Recent experimental results on electrode materials also suggest that carbon coating may give certain constraints on the functional materials, similar to the carbon walls of nanopores explained above.

\section{(a) Metallic silicon}

Carbon coating is very effective to exert the intrinsic functionality of metallic silicon as the anode material for LIBs, such as a high theoretical capacity (more than $3.5 \mathrm{~A} \mathrm{~h} \mathrm{~g}^{-1}$ ), by absorbing its large volume change (more than 300\%) during lithiation/delithiation and improving its relatively low electrical conductivity.

Particle sizes of $\mathrm{Si}$ as anode materials exhibited marked influences on rate and cycle performances of LIBs with $1 \mathrm{M}$ $\mathrm{LiPF}_{6} /(\mathrm{EC}+\mathrm{DEC}) .{ }^{69} \mathrm{Si}$ particles with the particle size of $c a .1 \mu \mathrm{m}$ (micron-sized $\mathrm{Si}$ ) showed abrupt decrease in capacity with the cycle number even at a small current density of $0.2 \mathrm{~A} \mathrm{~g}^{-1}$ due to the pulverization of Si particles. The poor cycle lifetimes of the micron-sized Si particles were attributed to the typical bulk like behavior. On the other hand, nano-sized Si particles with the size of $82 \mathrm{~nm}$ exhibited the remarkably enhanced coulombic efficiency at the 1st and following cycles. The capacity retention of the nano-sized Si particles was enhanced by carbon coating with a thickness of $c a .10 \mathrm{~nm}$ through a pressure-pulsed chemical vapor deposition (P-CVD) method; the carbon coating decreased the inner resistance. The particle morphology of the nano-sized Si particles and the carboncoated ones changed from spherical particles to nano-sized wrinkled structure after 20 charge/discharge (lithiation/delithiation) cycles (Fig. 19a and b). ${ }^{69,70}$ At the same time, the coated carbon was also deformed together with wrinkled Si, as evidenced by scanning transmission electron microscopy (STEM) imaging and energy dispersive X-ray spectroscopy (EDS) analysis. ${ }^{69}$ After 100 cycles, the wrinkled structure of both samples further transformed into an aggregated lump due to the repeated volumetric expansion and the subsequent agglomeration of pulverized $\mathrm{Si}$ particles (Fig. 19c). ${ }^{\text {70 }}$ The capacity fading accompanied by the structural deformation of the wrinkled Si was suppressed by limiting the capacity up to $1500 \mathrm{~mA} \mathrm{~h} \mathrm{~g}^{-1}$ during lithiation because of restricting the volumetric expansion to some extent. Similar structural transformation through wrinkled one and improved battery performances were observed on ball-milled $\mathrm{Si}$, which is more inexpensive than Si nanoparticles. ${ }^{70}$ On the ball-milled Si consisting of weakly aggregated primary particles with the size of about $47 \mathrm{~nm}$, the initial reversible capacity was improved reaching $c a$. $3000 \mathrm{~mA} \mathrm{~h} \mathrm{~g}^{-1}$ by carbon coating, as shown in Fig. 20a. By restricting the discharge capacity up to $1500 \mathrm{~mA} \mathrm{~h} \mathrm{~g}{ }^{-1}$, cycling with different current densities of $0.2-$ $5.0 \mathrm{~A} \mathrm{~g}^{-1}$ was possible on the carbon-coated Si up to at least 100 cycles, whereas ball-milled Si without carbon coating showed a marked capacity fading (Fig. 20b). Flaky Si nanoparticles (thickness of $c a .16 \mathrm{~nm}$ and lateral size of $0.2-1 \mu \mathrm{m}$ ) were produced from $\mathrm{Si}$ sawdust by beads-milling in isopropyl alcohol. Since the Si sawdust contained $4 \mathrm{wt} \%$ graphite, which came from the graphite substrate used for the cutting process of $\mathrm{Si}$ ingots, the graphite was homogeneously dispersed over the $\mathrm{Si}$ particles after a beads-milling process. ${ }^{71}$ Although their structure was converted into nanoflake morphology through a milling process, they could be transformed to wrinkled morphology by cycling of lithiation/de-lithiation and demonstrated better performances as an anode of LIBs. The CVD of the nanoflake Si was also examined, and the resulting material exhibited the enhanced rate capability at $5 \mathrm{~A} \mathrm{~g}^{-1}$ under the limiting capacity of $1500 \mathrm{~mA} \mathrm{~h}^{-1}$ during lithiation, reaching almost the same value as that at $0.2 \mathrm{~A} \mathrm{~g}^{-1}$. The enhanced rate capability was attributed to the large continuous structure formed by carbon coating. The carbon layer on Si particles is supposed to work as a buffer between neighboring Si nanoparticles even during marked morphology change from spherical or flaky to wrinkled, in other words, by confining $\mathrm{Si}$ nanoparticles within coating carbon.

Thin Si flakes were synthesized by CVD of silane $\left(\mathrm{SiH}_{4}\right)$ gas on the cubic crystals of $\mathrm{NaCl}$ at $550{ }^{\circ} \mathrm{C}$, followed by dissolution of $\mathrm{NaCl}$. The thickness and lateral size of the Si flakes was controlled to be $50 \mathrm{~nm}$ and a micrometer, respectively. ${ }^{72}$ Carbon coating of the Si flakes was performed by heating in acetylene gas at $900{ }^{\circ} \mathrm{C}$, resulting in the carbon content of $7 \mathrm{wt} \%$ and the thickness of about $10 \mathrm{~nm}$. The non-porous structure of the pristine and carbon-coated Si flakes with a low surface area of ca. $10 \mathrm{~m}^{2} \mathrm{~g}^{-1}$ suppressed excessive SEI formation and reduced initial irreversible capacity (Fig. 21a), in comparison with that of the commercially available $\mathrm{Si}$ nanoparticles. Their initial reversible capacities reached 2943 and $2255 \mathrm{~mA} \mathrm{~h} \mathrm{~g}^{-1}$, corresponding to the initial coulombic efficiency of $87.2 \%$ and 

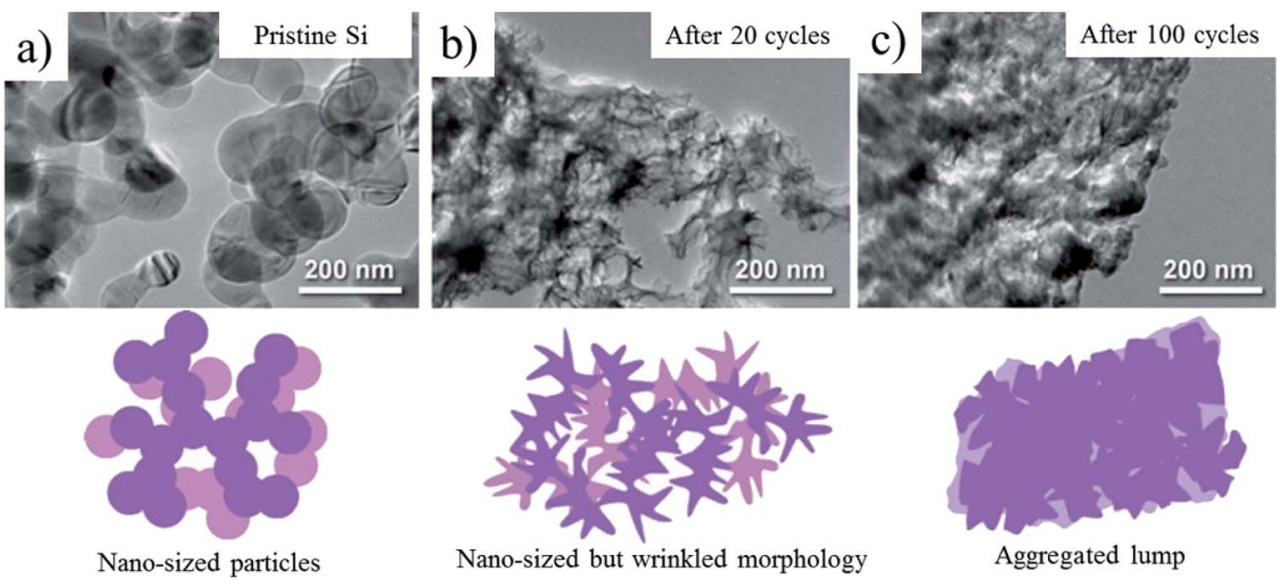

Fig. 19 TEM images and morphology illustrations of nano-sized Si after cycling of lithiation/de-lithiation. Adapted from ref. 70 with permission from Elsevier.
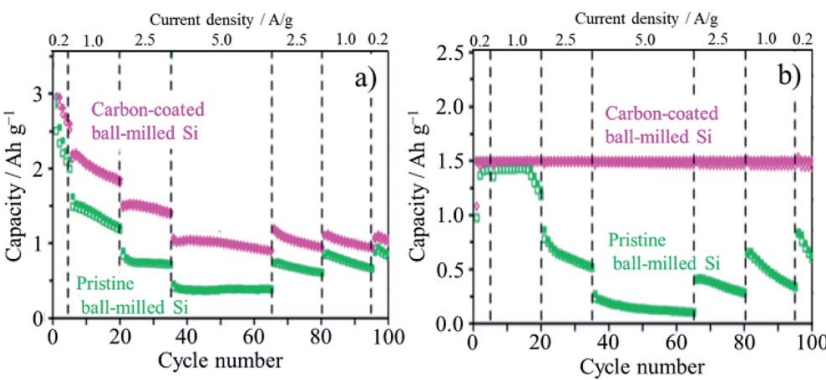

Fig. 20 Capacity changes with cycling with different current densities on pristine ball-milled Si and carbon-coated one: (a) without and (b) with the capacity restriction to $1.5 \mathrm{~A} \mathrm{~h} \mathrm{~g}^{-1}$. Adapted from ref. 70 with permission from Elsevier.

92.3\%, respectively in 1.3 $\mathrm{M} \mathrm{LiPF}_{6} /(\mathrm{EC}+\mathrm{DEC})$. As shown in Fig. 21b, the carbon-coated Si flakes delivered a steady rate performance around $2000 \mathrm{~mA} \mathrm{~h} \mathrm{~g}^{-1}$ up to $10 \mathrm{C}$ rate, whereas the pristine Si flakes show the inferior rate capability. The full cell coupled with a $\mathrm{LiCoO}_{2}$ cathode shows a steady cycle performance at $0.5 \mathrm{C}$ rate for the carbon-coated Si flakes, while the reversible capacity of the pristine Si flakes decayed drastically (Fig. 21c). The carbon layer on Si flakes works not only to improve the electrical conductivity in the anode but also to buffer the large expansion of Si during lithiation.

The structural deformation of the carbon-coated Si flake was monitored by in situ TEM under a bias of $-3 \mathrm{~V}$ and $3 \mathrm{~V}$, respectively, where a flake was mounted on a Pt wire connected to the $\mathrm{Li}_{2} \mathrm{O} / \mathrm{Li}$ probe; the $\mathrm{Li}$ metal and the $\mathrm{LiO}_{2}$ layer serve as the counter electrode and the solid electrolyte, respectively. ${ }^{72}$ The structural deformation of the flake in the first two lithiation/delithiation cycles was schematically illustrated in Fig. 22. During the first lithiation, the flake showed anisotropic swelling, with only $9.7 \%$ expansion along lateral direction but about $200 \%$ in thickness upon full lithiation $\left(\mathrm{Li}_{15} \mathrm{Si}_{4}\right)$, giving $\sim 270 \%$ volumetric swelling. By de-lithiation, the flake rippled along the lateral direction of the flake and the flake itself was significantly buckled. The second lithiation smoothed out the ripples and the de-lithiation gave severe buckling to the flake, while maintaining its 2D morphology without fracture. In contrast, the pristine Si flake without carbon coating swelled into the lateral direction as much as $31.9 \%$ after the first lithiation and could not recover its original dimensions during de-lithiation,
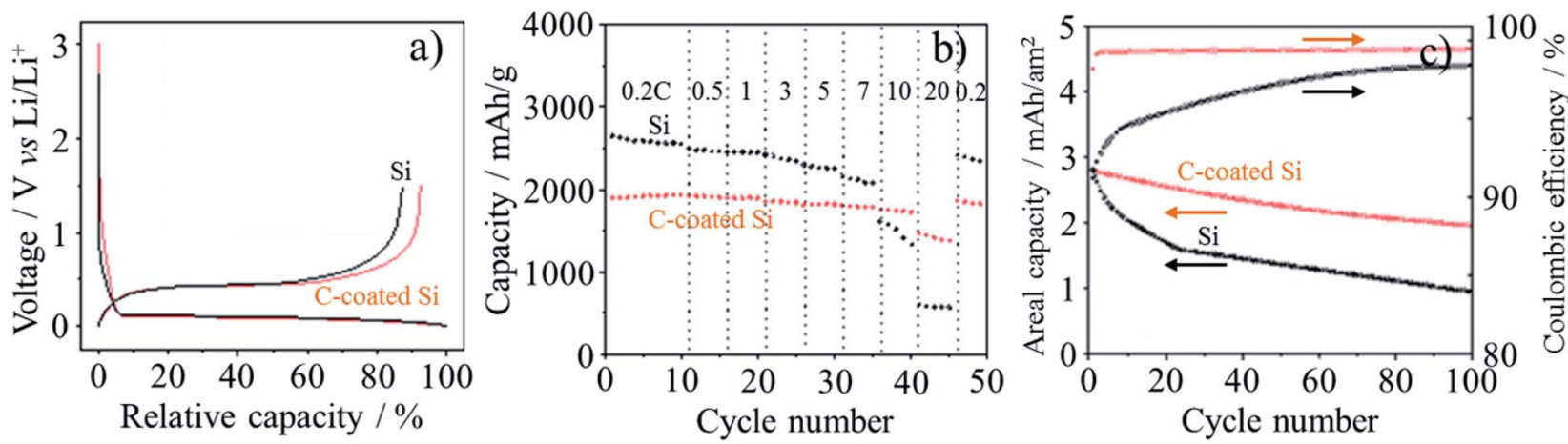

Fig. 21 Carbon-coated Si flakes in comparison with the pristine Si flakes: (a) the first charge/discharge curves, (b) rate capability at different Crates and (c) cycle performance of the cell coupled with a $\mathrm{LICOO}_{2}$ cathode at $0.5 \mathrm{C}$ rate. Adapted from ref. 72 with permission from Nature Publishing Group. 


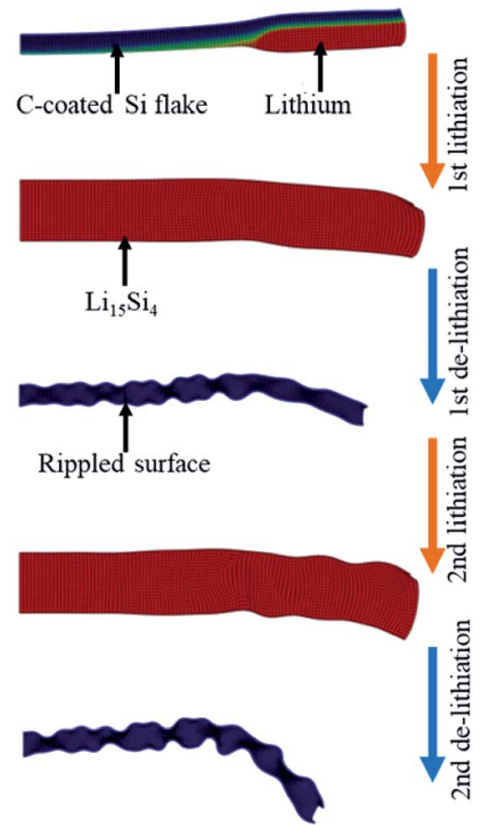

Fig. 22 Schematic illustration of morphology change during lithiation/ de-lithiation process. Adapted from ref. 72 with permission from Nature Publishing Group.

preserving the swollen morphology and sharp edges generated during lithiation. The fact that lithiation of the pristine Si took longer times under higher bias than those of the carbon-coated Si flake indicates the relatively poor rate capability. The distinct difference in morphology change during the lithiation/delithiation cycle between the pristine and carbon-coated flakes is reasonably supposed to be due to the carbon layer coating, suggesting certain mechanical constraint of the carbon layers on the deformation of Si flakes.

B-doped $\mathrm{Si} / \mathrm{SiO}_{2}$ composites were prepared from the mixture of ball-milled $\mathrm{SiO}_{2}$ and $\mathrm{B}_{2} \mathrm{O}_{3}$ powder $(20: 1$ by mole $)$ at $950{ }^{\circ} \mathrm{C}$ in $\mathrm{Ar}$, where B-doped crystalline Si nanoparticles with the size of about $15 \mathrm{~nm}$ were dispersed in amorphous $\mathrm{SiO}_{2}$ particles (particles size of about $3 \mu \mathrm{m}$ ). ${ }^{73}$ Carbon coating of the composite by CVD of acetylene at $700{ }^{\circ} \mathrm{C}$ resulted in high cyclic performance of a hybrid cell coupled with mesoporous carbon spheres as a cathode using a $1 \mathrm{M} \mathrm{LiPF}_{6} /(\mathrm{EC}+\mathrm{DEC}+\mathrm{DMC})$ electrolyte (lithium-ion capacitor, LIC), which delivered an energy density of $128 \mathrm{~W} \mathrm{~h} \mathrm{~kg}^{-1}$ at a power density of $1.23 \mathrm{~kW}$ $\mathrm{kg}^{-1}$ and even $89 \mathrm{~W} \mathrm{~h} \mathrm{~kg}^{-1}$ at $9.7 \mathrm{~kW} \mathrm{~kg}^{-1}$ with the voltage window of 2.0-4.5 V. Amorphous $\mathrm{SiO}_{2}$ matrix of the composites was supposed to work as a buffer layer for a large volume change of Si during lithiation/de-lithiation. In addition, boron-doping into $\mathrm{Si}$ increases the electrical conductivity of $\mathrm{Si}$ and enables fast charge transfer, necessary for high power density. Furthermore, the electrical conductivity and cycle lifetimes of Si were markedly improved by carbon coating. Si-included carbon composites were prepared from wasted glass (Si source) and wasted polyvinyl butyral (carbon source), both of which were derived from windshields with a polyvinyl butyral layer sandwiched by two glasses. ${ }^{74}$ The wasted glass separated from the polyvinyl butyral was reduced to $\mathrm{Si}$ by $\mathrm{Mg}$ powder as a reducing reagent at $650{ }^{\circ} \mathrm{C}$ for $6 \mathrm{~h}$ under $\mathrm{Ar}$ atmosphere, and the byproducts $\left(\mathrm{Mg}_{2} \mathrm{Si}\right.$ and $\left.\mathrm{Mg}_{2} \mathrm{SiO}_{4}\right)$ and the unreacted $\mathrm{SiO}_{2}$ were removed by $\mathrm{HNO}_{3}$ and $\mathrm{HF}$ etching, respectively. The carbon coating was performed by mixing the obtained Si nanoparticles and the polyvinyl butyral and their subsequent heat treatment at $500{ }^{\circ} \mathrm{C}$ for $4 \mathrm{~h}$. Its LIB performance was measured in $1 \mathrm{M}$ $\mathrm{LiPF}_{6} /(\mathrm{EC}+\mathrm{PC})$ electrolyte solution. The reversible capacity of the non-carbon-coated $\mathrm{Si}$ in the first charge/discharge cycle reached $3336 \mathrm{~mA} \mathrm{h \quad g^{-1 }}$ with irreversible capacity of $489 \mathrm{~mA} \mathrm{~h} \mathrm{~g}^{-1}$, but it decayed rapidly with the number of cycling measured at $420 \mathrm{~mA} \mathrm{~g}^{-1}$, down to less than $1000 \mathrm{~mA} \mathrm{~h} \mathrm{~g}^{-1}$ after 50 cycles. In contrast, the carbon-coated $\mathrm{Si}$ with a carbon content of $60 \mathrm{wt} \%$ showed the initial reversible capacity of $856 \mathrm{~mA} \mathrm{~h} \mathrm{~g}^{-1}$, while its capacity retention reached $84 \%$ at the 300th cycle. Although its initial reversible capacity was less than $1000 \mathrm{~mA} \mathrm{~h} \mathrm{~g}{ }^{-1}$, the capacity per unit mass of $\mathrm{Si}$ is calculated to be over $2000 \mathrm{~mA} \mathrm{~h} \mathrm{~g}{ }^{-1}$. The carbon matrix stabilized the $\mathrm{Si}$ nanoparticles and enhanced electrical conductivity of the electrode, which was supported by the result of the impedance analysis. The composite of $\mathrm{Si} / \mathrm{rGO}$ was prepared from a colloidal mixture of wasted Si sludge containing SiC from the waferslicing saw with GO by aerosol spray pyrolysis with thermal reduction of GO. ${ }^{75}$ The colloidal mixture was sprayed into a tubular furnace by ultrasonic nebulizer, and at the same time, unnecessary $\mathrm{SiC}$ was separated from the droplet because the $\mathrm{Si}$ particles have a lighter density and smaller sizes than the SiC particles. The as-prepared composite has ball-like morphology and the $\mathrm{Si}$ particles are located inside the rGO shell. The composite prepared from the colloidal mixture with $0.1 \mathrm{wt} \% \mathrm{GO}$ delivered the reversible capacity of about $1600 \mathrm{~mA} \mathrm{~h} \mathrm{~g}^{-1}$ in the initial charge/discharge cycles by retaining the capacity of about $1000 \mathrm{~mA} \mathrm{~h} \mathrm{~g}^{-1}$ after 50 cycles. The composite prepared from the mixture with $0.4 \mathrm{wt} \% \mathrm{GO}$ gave much better cyclability although the capacity became smaller ( $\left.c a .700 \mathrm{~mA} \mathrm{~h} \mathrm{~g}^{-1}\right)$.

Carbon-coated $\mathrm{Si}$ nanowires were synthesized from the mixture of bis(bis(trimethylsilyl)amino)tin, $\operatorname{Sn}(\mathrm{HMDS})_{2}$, and monophenylsilane (MPS) with different mole ratios (Sn/Si of 1/ 16 to $1 / 64) .^{76}$ The reaction proceeded under supercritical fluid condition in anhydrous toluene solution at $490{ }^{\circ} \mathrm{C}$ and 10.3 MPa, followed by the carbonization at $900{ }^{\circ} \mathrm{C}$ under $\mathrm{N}_{2} / \mathrm{H}_{2}$ gas flow. At first, MPS decomposed to atomic Si and high order phenylsilane through disproportionation reaction, while Sn(HMDS $)_{2}$ decomposed to Sn nanoparticles which worked as
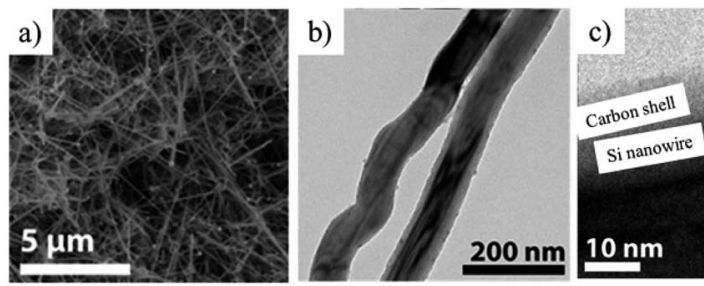

Fig. 23 Carbon-coated Si nanowires prepared from the mixture of $\mathrm{Sn}(\mathrm{HMDS})_{2}$ and MPS in Sn/Si mole ratio of 1/22 after carbonization at $900{ }^{\circ} \mathrm{C}$ : (a) SEM, (b) TEM and (c) HRTEM images. Adapted with permission from ref. 76. Copyright 2013 American Chemical Society. 
Charge/discharge curves

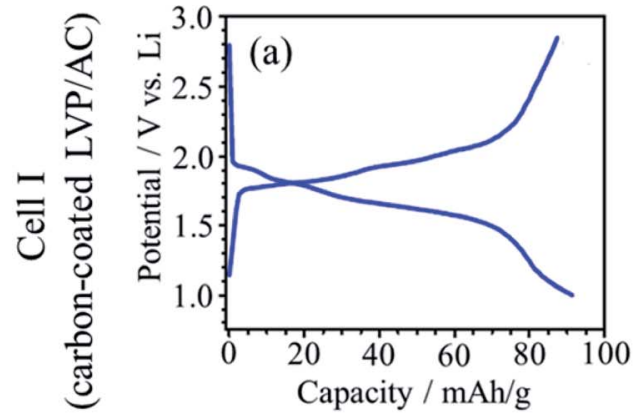

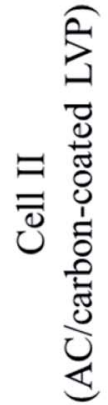

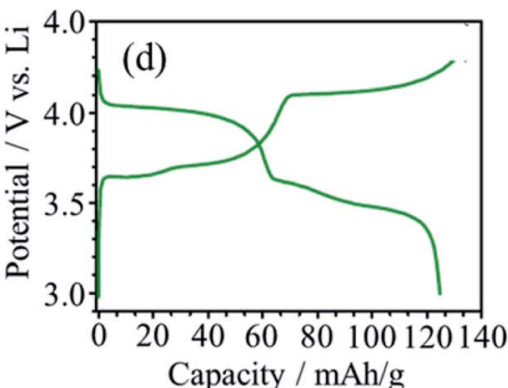

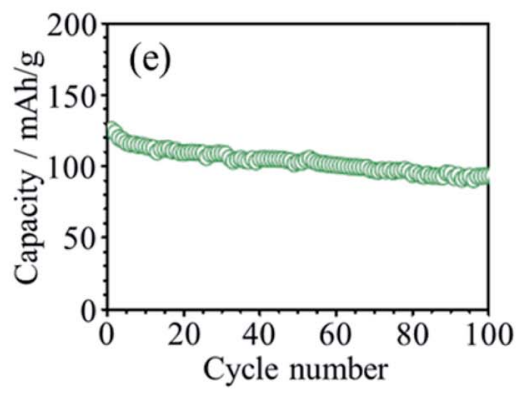

Cyclic performance

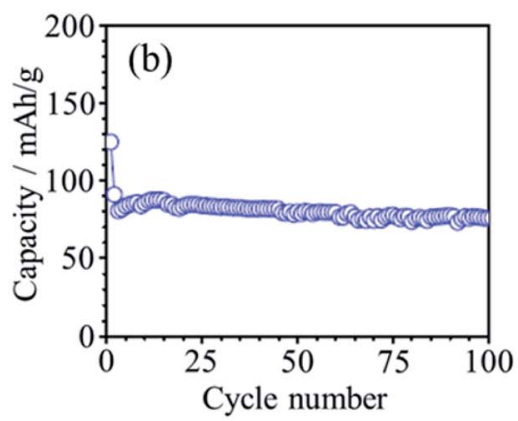

Cycle number
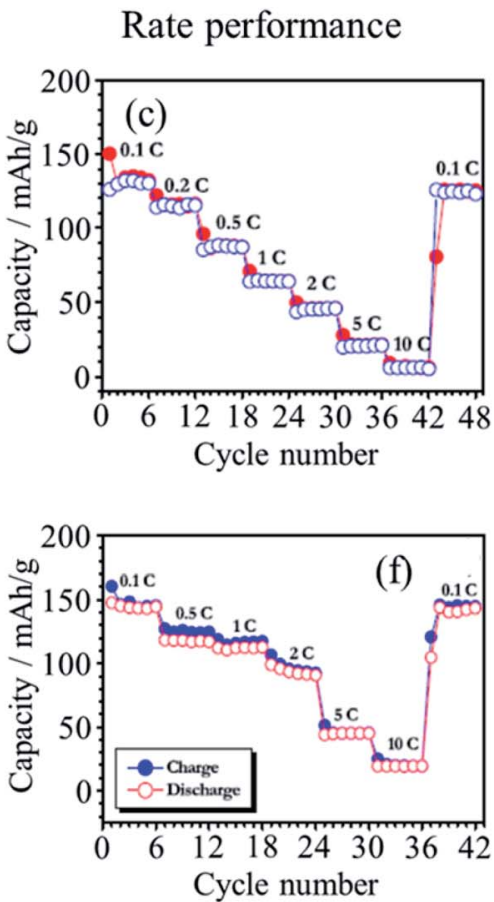

Fig. 24 Results of galvanostatic charge/discharge analysis of carbon-coated LVP (anode)//AC (cell I) and AC//carbon-coated LVP (cathode) (cell II) in $1 \mathrm{M} \mathrm{LiPF}_{6} /\left(\mathrm{EC}+\mathrm{DEC}\right.$ ) electrolyte: (a and d) charge/discharge curve at $100 \mathrm{~mA} \mathrm{~g}^{-1}$ rate. (b and e) Cyclic performance at $100 \mathrm{~mA} \mathrm{~g} \mathrm{~g}^{-1}$ rate, and ( $c$ and f) rate performance $\left(1 \mathrm{C}=131 \mathrm{~mA} \mathrm{~h} \mathrm{~g}^{-1}\right.$ ). Adapted from ref. 77 with permission from Elsevier.

a seed to form eutectic with Si for growing Si nanowires. The high order phenyl silane byproduct polymerized on the surface of the $\mathrm{Si}$ nanowires and the resulting polyphenylsilane was converted to carbon shells during the heat treatment at $900{ }^{\circ} \mathrm{C}$. The morphology of the carbon-coated Si nanowires highly depends on the $\mathrm{Sn} / \mathrm{Si}$ molar ratio, and the nanowires prepared below a $\mathrm{Sn} / \mathrm{Si}$ molar ratio of $1 / 32$ before the heat treatment were heavily kinked and covered by thick polyphenylsilane shell. The carbon-coated Si nanowires prepared with a $\mathrm{Sn} / \mathrm{Si}$ molar ratio of $1 / 22$ showed the markedly straighter and thinner shell, and the carbon shell retained the uniform thickness after the heat treatment (Fig. 23). This composite exhibited a high capacity over $2000 \mathrm{~mA} \mathrm{~h} \mathrm{~g}^{-1}$, with nearly $96 \%$ coulombic efficiency when cycled at a slow rate of $0.1 \mathrm{C}$ for 100 cycles. Moreover, a stable capacity of about $1300 \mathrm{~mA} \mathrm{~h} \mathrm{~g}^{-1}$ with more than $98 \%$ coulombic efficiency was attained after 100 cycles when measured at 1C. In contrast, the nanowires without the heat treatment exhibited no capacity after 20 cycles at $1 \mathrm{C}$ rate, although the capacity at the first cycles was about $300 \mathrm{~mA} \mathrm{~h} \mathrm{~g}^{-1}$. The in situ TEM observation of the lithiation of the carbon-coated Si nanowires indicated that uniform carbon coating on the Si nanowires prevented full lithiation while nonuniform and incomplete carbon coating allowed the Si nanowire to be fully lithiated, relieving the stress created by expanding Si nanowire.

\section{(b) Lithium compounds}

LICs with two configurations were constructed by using carboncoated $\mathrm{Li}_{3} \mathrm{~V}_{2}\left(\mathrm{PO}_{4}\right)_{3}(\mathrm{LVP})$ as either anode or cathode by coupling with $\mathrm{AC}$ as the counter electrodes using $1 \mathrm{M} \mathrm{LiPF}_{6} /(\mathrm{EC}+\mathrm{DEC})$ electrolyte, ${ }^{77}$ because a monoclinic LVP can serve as both an anode $\left(\mathrm{V}^{3+} / \mathrm{V}^{2+}\right)$ and as a cathode $\left(\mathrm{V}^{3+} / \mathrm{V}^{5+}\right) \cdot^{78,79}$ In the cell I (carbon-coated LVP(anode)//AC), the principal reactions during charge/discharge are the insertion/de-insertion of $\mathrm{Li}^{+}$at the carbon-coated LVP as the anode and the adsorption/desorption of $\mathrm{PF}_{6}{ }^{-}$at the $\mathrm{AC}$ as the cathode. In the cell $\mathrm{II}(\mathrm{AC} / /$ carboncoated LVP (cathode)), however, the de-insertion/re-insertion of $\mathrm{Li}^{+}$at the carbon-coated LVP as the cathode and the adsorption/desorption of $\mathrm{Li}^{+}$at the $\mathrm{AC}$ anode. Charge/discharge curves at a current density of $100 \mathrm{~mA} \mathrm{~g}^{-1}$ exhibit the multiple plateaus, corresponding to the redox reactions on the carboncoated LVP (Fig. 24a and d). The cycle performances measured at $100 \mathrm{~mA} \mathrm{~g}^{-1}$ (Fig. 24b and e) and rate performances at different $\mathrm{C}$ rates (Fig. $24 \mathrm{c}$ and $\mathrm{f}$ ) of the two cells were compared. Even though the principal electrochemical reactions at the electrodes are different between the two cells, their performance are very similar. The energy and power densities
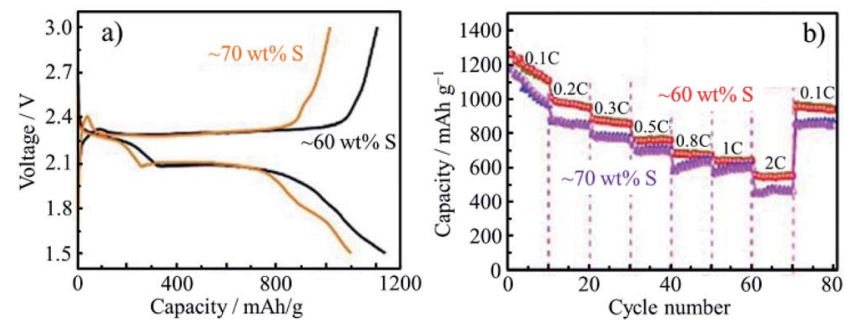

Fig. $25 \mathrm{Li}-\mathrm{S}$ batteries composed of carbon-coated rGO flakes: (a) charge/discharge curves and (b) rate performances for the cathodes with different S-contents. Adapted from ref. 83 with permission from the Royal Society of Chemistry. 
for the two cells were not so much different. The presence of the phosphate group increases the redox potential but decreases the electrical conductivity. The carbon coating improves the electrical conductivity of the LVP and facilitates the charge transfer between the LVP and the current collector, realizing high rate performance.

Carbon-coated $\mathrm{Li}_{2} \mathrm{MnSiO}_{4}$ was synthesized by solid-state reaction of the mixture of $\mathrm{LiOH}, \mathrm{MnCO}_{3}$ and $\mathrm{SiO}_{2}$ with adipic acid at $900{ }^{\circ} \mathrm{C}$. Its LIC cell coupled with AC anode in $1 \mathrm{M} \mathrm{LiPF}_{6} /$ $(\mathrm{EC}+\mathrm{DMC})$ delivered the capacitance of $43.2 \mathrm{~F} \mathrm{~g}^{-1}$ at $1 \mathrm{~mA} \mathrm{~cm}^{-2}$ and the energy density of $54 \mathrm{~W} \mathrm{~h} \mathrm{~kg}^{-1}$ at $0.15 \mathrm{~kW} \mathrm{~kg}^{-1}$ with the retention of about $85 \%$ after 1000 cycles. ${ }^{80}$ Carbon-coated $\mathrm{Li}_{2}$ $\mathrm{FeSiO}_{4}$ was also synthesized as anode materials for LICs by the same procedure and exhibited almost the same LIC performances as the carbon-coated $\mathrm{Li}_{2} \mathrm{MnSiO}_{4}{ }^{81}$ Adipic acid used in these studies is the carbon source to improve the electrical conductivity between the particles of active materials by carbon coating, thus achieving high-power density cathodes for hybrid super capacitors. Carbon coating of $\mathrm{H}_{2} \mathrm{Ti}_{12} \mathrm{O}_{25}$, which was prepared from $\mathrm{Na}_{2} \mathrm{CO}_{3}$ and $\mathrm{TiO}_{2}$ at a molar ratio of $1: 3$, was performed by mixing with beta cyclodextrin (4.5 wt\%) as a carbon source and subsequent calcination at $800{ }^{\circ} \mathrm{C}$ for $2 \mathrm{~h}$. The thickness of the carbon layer was determined to be $3.09 \mathrm{~nm}$ by TEM observation, and the carbon coating was effective to improve LIC performance, giving negligible capacitance decrease after 100 cycles and energy density of $38.8 \mathrm{~W} \mathrm{~h} \mathrm{~kg}^{-1}$ at a power density of $0.18 \mathrm{~kW} \mathrm{~kg}^{-1}$ in $1.5 \mathrm{M} \mathrm{LiBF}_{4}(\mathrm{EC}+\mathrm{DMC}){ }^{82}$ The carbon layer was supposed to not only enhance the electrical conductivity but also suppress the swollen phenomenon, which was caused by the reduction decomposition between $\mathrm{H}_{2} \mathrm{Ti}_{12} \mathrm{O}_{25}$ and the electrolyte solution, generating $\mathrm{C}_{2} \mathrm{H}_{4}, \mathrm{CO}$, and $\mathrm{CH}_{4}$ gases.

\section{(c) Reduced graphene oxides}

Coating of N-doped porous carbon on rGO was performed by hydrothermal reaction of aqueous suspension of GO containing glucose and pyrrole at $180{ }^{\circ} \mathrm{C}$, followed by $\mathrm{KOH}$ activation at $900{ }^{\circ} \mathrm{C}^{.33}$ The rGO was sandwiched by $\mathrm{N}$-doped porous carbon on both sides of the rGO flakes and the resulting composite had a porous sheet-like structure. The composite had a high $S_{\mathrm{BET}}$ of $2680 \mathrm{~m}^{2} \mathrm{~g}^{-1}$ and a $V_{\text {total }}$ of $1.82 \mathrm{~cm}^{3} \mathrm{~g}^{-1}$, possible to adsorb sulfur up to $70 \mathrm{wt} \%$ for a cathode material of Li-S batteries. The hybrids with 60 and $70 \mathrm{wt} \% \mathrm{~S}$ showed the initial discharge capacity of 1236 and $1099 \mathrm{~mA} \mathrm{~h} \mathrm{~g}^{-1}$, with coulombic efficiencies of 94.5 and $89.2 \%$, respectively (Fig. 25a). The relatively low capacity and coulombic efficiency of the latter hybrid (70 wt\% S) is attributed to the shuttling of the sulfide outside the pores. Moreover, the excess sulfur content decreased the cycle stability of the electrode (Fig. 25b) and increased the diffusion resistance due to the hindered ion transfer, which was supported by the results of their impedance analysis. The former hybrid (60 wt $\%$ S) could tightly hold polysulfide particles to avoid their shuttling between electrodes (in other words, confining polysulfide particles), as well as to improve electrical conductivity of the cathode.

\section{Concluding remarks}

To understand the details on the constraint spaces formed in carbon materials, many problems remain unsolved, because most papers mentioned in the present review taught us just the experimental results: the procedures of material modifications, the improved functions of the resulting composites, etc. For further development of this research field, understanding the fundamentals of constraint spaces is crucial. For examples, what kind of constraint is effective, whether constraint is due to the limitation in size of the encapsulated materials, mechanical constraint due to unbalance in thermal expansion between the materials and matrix carbon walls, chemical interaction of the materials with edges and/or functional groups on carbon walls or others. In addition, we have to know how these constraints can be controlled and designed, how the constraint spaces intrinsically influence the functions of the materials, etc.

Carbon nanotubes provide us well-defined spaces with various controllable parameters for matrix carbon, including their diameter and length, layer number of the wall, etc., in addition to the possibility for the nanotubes after confinement of the material to be directly observed by microscopic techniques. However, it has to be pointed out that the nanotube wall is limited to an almost perfect but highly-curved layer of carbon hexagons (we may say "graphene" layer, but strongly curved), in addition to the high cost and limited amount of carbon nanotubes. Zeolitetemplated carbons are composed of ordered micropores with walls of defective graphene-like layers, but they are not commercialized yet and their synthesis procedure is complicated. Also the carbons prepared by using either mesoporous silica or block copolymer surfactants as the templates provide us ordered channels with mesopore-sized diameters, but the walls of these mesoporous carbons consist of amorphous carbon because carbon precursors for these templates are almost limited to phenolic resins. It is not certain whether only carbon coating of the materials can create constraint space or not, however, carbon coating techniques give us variable carbon walls on the target materials; dense carbon films with controlled thickness can be deposited on the materials by CVD, and porous carbon films can form the mixture of particles of the materials with various resins (carbon precursors), such as thermosetting and thermoplastic resins. Since carbon materials are endowed with the structural and textural diversities, as pointed out above, there are infinite combinations for synthesizing the composites using versatile porous carbons. Moreover, the electrical conductivity of carbon materials can widen their applications toward electronic devices and electrocatalysts.

\section{Conflicts of interest}

There are no conflicts to declare. 


\section{Acknowledgements}

H. M. acknowledges the financial support from JSPS KAKENHI grant number $18 \mathrm{~K} 04697$.

\section{References}

1 M. Inagaki, F. Kang, M. Toyoda and H. Konno, Advanced Materials Science and Engineering of Carbon, Tsinghua University Press and Elsevier, 2014.

2 M. Inagaki and F. Kang, Materials Science and Engineering of Carbon: Fundamentals, Tsinghua University Press and Elsevier, 2nd edn, 2014.

3 Y. Yang, T. Le, F. Kang and M. Inagaki, Carbon, 2017, 111, 546-568.

4 M. Inagaki, H. Orikasa and T. Morishita, $R S C A d v ., 2011,1$, 1620-1640.

5 M. Inagaki, M. Toyoda, Y. Soneda, S. Tsujimura and T. Morishita, Carbon, 2016, 107, 448-473.

6 B. W. Smith, M. Monthioux and D. E. Luzzi, Nature, 1998, 396, 323-324.

7 B. W. Smith and D. E. Luzzi, Chem. Phys. Lett., 2000, 321, 169-174.

8 H. Kataura, Y. Maniwa, M. Abe, A. Fujiwara, T. Kodama, K. Kikuchi, H. Imahori, Y. Misaki, S. Suzuki and Y. Achiba, Appl. Phys. A, 2002, 74, 349-354.

9 G. Ning, N. Kishi, H. Okimoto, M. Shiraishi, T. Sugai and H. Shinohara, J. Phys. Chem. C, 2007, 111, 14652-14657.

10 S. Okada, S. Saito and A. Oshiyama, Phys. Rev. Lett., 2001, 86, 3835-3838.

11 S. Kawasaki, Y. Matsuoka, T. Yokomae, Y. Nojima, F. Okino, H. Touhara and H. Kataura, Carbon, 2005, 43, 37-45.

12 M. Chorro, S. Rols, J. Cambedouzou, L. Alvarez, R. Almairac, J. L. Sauvajol, J. L. Hodeau, L. Marques, M. Mezouar and H. Kataura, Phys. Rev. B, 2006, 74, 205425.

13 H. Kataura, Y. Maniwa, T. Kodama, K. Kikuchi, K. Hirahara, K. Suenaga, S. Iijima, S. Suzuki, Y. Achiba and W. Krätschmer, Synth. Met., 2001, 121, 1195-1196.

14 S. Bandow, M. Takizawa, K. Hirahara, M. Yudasaka and S. Iijima, Chem. Phys. Lett., 2001, 337, 48-54.

15 H. Muramatsu, T. Hayashi, Y. A. Kim, D. Shimamoto, M. Endo, V. Meunier, B. G. Sumpter, M. Terrones and M. S. Dresselhaus, Small, 2009, 5, 2678-2682.

16 E. Hernández, V. Meunier, B. W. Smith, R. Rurali, H. Terrones, M. Buongiorno Nardelli, M. Terrones, D. E. Luzzi and J. C. Charlier, Nano Lett., 2003, 3, 1037-1042.

17 Y. A. Kim, H. Muramatsu, T. Hayashi, M. Endo, M. Terrones and M. S. Dresselhaus, Chem. Phys. Lett., 2004, 398, 87-92.

18 R. Pfeiffer, H. Kuzmany, C. Kramberger, C. Schaman, T. Pichler, H. Kataura, Y. Achiba, J. Kürti and V. Zólyomi, Phys. Rev. Lett., 2003, 90, 225501.

19 H. Muramatsu, D. Shimamoto, T. Hayashi, Y. A. Kim, M. Terrones, M. Endo and M. S. Dresselhaus, Adv. Mater., 2011, 23, 1761-1764.

20 M. Endo, T. Hayashi, H. Muramatsu, Y.-A. Kim, H. Terrones, M. Terrones and M. S. Dresselhaus, Nano Lett., 2004, 4, 1451-1454.
21 H. Muramatsu, T. Hayashi, K. Y. Ahm, M. Terrones and M. Endo, Chem. Phys. Lett., 2006, 432, 240-244.

22 K. Méténier, S. Bonnamy, F. Béguin, C. Journet, P. Bernier, M. Lamy de La Chapelle, O. Chauvet and S. Lefrant, Carbon, 2002, 40, 1765-1773.

23 K. Hirahara, K. Suenaga, S. Bandow, H. Kato, T. Okazaki, H. Shinohara and S. Iijima, Phys. Rev. Lett., 2000, 85, 53845387.

24 L. Guan, K. Suenaga, Z. Shi, Z. Gu and S. Iijima, Phys. Rev. Lett., 2005, 94, 045502.

25 S. Kawasaki, Y. Iwai and M. Hirose, Mater. Res. Bull., 2009, 44, 415-417.

26 S. Ahn, Y. Kim, Y. Nam, H. Yoo, J. Park, Y. Park, Z. Wang, Z. Shi and Z. Jin, Phys. Rev. B, 2009, 80, 165426.

27 H. Song, Y. Ishii, A. Al-zubaidi, T. Sakai and S. Kawasaki, Phys. Chem. Chem. Phys., 2013, 15, 5767-5770.

28 Y. Yoshida, Y. Ishii, N. Kato, C. Li and S. Kawasaki, J. Phys. Chem. C, 2016, 120, 20454-20461.

29 K. Urita, Y. Shiga, T. Fujimori, T. Iiyama, Y. Hattori, H. Kanoh, T. Ohba, H. Tanaka, M. Yudasaka, S. Iijima, I. Moriguchi, F. Okino, M. Endo and K. Kaneko, J. Am. Chem. Soc., 2011, 133, 10344-10347.

30 T. Fujimori, A. Morelos-Gómez, Z. Zhu, H. Muramatsu, R. Futamura, K. Urita, M. Terrones, T. Hayashi, M. Endo, S. Young Hong, Y. Chul Choi, D. Tománek and K. Kaneko, Nat. Commun., 2013, 4, 2162.

31 H. Luo, S. Desgreniers, Y. K. Vohra and A. L. Ruoff, Phys. Rev. Lett., 1991, 67, 2998-3001.

32 T. Takenobu, T. Takano, M. Shiraishi, Y. Murakami, M. Ata, H. Kataura, Y. Achiba and Y. Iwasa, Nat. Mater., 2003, 2, 683688.

33 Y. Ishii, K. Tashiro, K. Hosoe, A. Al-zubaidi and S. Kawasaki, Phys. Chem. Chem. Phys., 2016, 18, 10411-10418.

34 C. Li, Y. Ishii, S. Inayama and S. Kawasaki, Nanotechnology, 2017, 28, 355401.

35 K. Yanagi, Y. Miyata and H. Kataura, Adv. Mater., 2006, 18, 437-441.

36 S. Kawasaki, Y. Iwai and M. Hirose, Carbon, 2009, 47, 10811086.

37 L. Guan, Z. Shi, M. Li and Z. Gu, Carbon, 2005, 43, 27802785.

38 Y. Li, R. Hatakeyama, T. Kaneko and T. Okada, Jpn. J. Appl. Phys., 2006, 45, L428-L431.

39 Y. F. Li, R. Hatakeyama, T. Kaneko, T. Izumida, T. Okada and T. Kato, Nanotechnology, 2006, 17, 4143-4147.

40 H. Shiozawa, T. Pichler, A. Grüneis, R. Pfeiffer, H. Kuzmany, Z. Liu, K. Suenaga and H. Kataura, Adv. Mater., 2008, 20, 1443-1449.

41 L.-J. Li, A. N. Khlobystov, J. G. Wiltshire, G. A. D. Briggs and R. J. Nicholas, Nat. Mater., 2005, 4, 481-485.

42 M. S. P. Sansom and P. C. Biggin, Nature, 2001, 414, 157-159. 43 G. Hummer, J. C. Rasaiah and J. P. Noworyta, Nature, 2001, 414, 188-190.

44 K. Koga, G. T. Gao, H. Tanaka and X. C. Zeng, Nature, 2001, 412, 802-805.

45 Y. Maniwa, H. Kataura, M. Abe, S. Suzuki, Y. Achiba, H. Kira and K. Matsuda, J. Phys. Soc. Jpn., 2002, 71, 2863-2866. 
46 H. Kyakuno, K. Matsuda, H. Yahiro, Y. Inami, T. Fukuoka, Y. Miyata, K. Yanagi, Y. Maniwa, H. Kataura, T. Saito, M. Yumura and S. Iijima, J. Chem. Phys., 2011, 134, 244501. 47 T. Ohba, S.-i. Taira, K. Hata and H. Kanoh, J. Phys. Chem. Lett., 2013, 4, 1211-1215.

48 H. Itoi, S. Hayashi, H. Matsufusa and Y. Ohzawa, Chem. Commun., 2017, 53, 3201-3204.

49 H. Itoi, S. Maki, T. Ninomiya, H. Hasegawa, H. Matsufusa, S. Hayashi, H. Iwata and Y. Ohzawa, Nanoscale, 2018, 10, 9760-9772.

50 H. Itoi, Y. Yasue, K. Suda, S. Katoh, H. Hasegawa, S. Hayashi, M. Mitsuoka, H. Iwata and Y. Ohzawa, ACS Sustainable Chem. Eng., 2017, 5, 556-562.

$51 \mathrm{H}$. Itoi, H. Hasegawa, H. Iwata and Y. Ohzawa, Sustainable Energy Fuels, 2018, 2, 558-565.

52 T. Le, Y. Yang, L. Yu, Z.-h. Huang and F. Kang, Sci. Rep., 2016, 6, 37368.

53 P. Przygocki, Q. Abbas, P. Babuchowska and F. Béguin, Carbon, 2017, 125, 391-400.

54 G. Lota, K. Fic and E. Frackowiak, Electrochem. Commun., 2011, 13, 38-41.

55 T. Morishita, T. Hirabayashi, T. Okuni, N. Ota and M. Inagaki, J. Power Sources, 2006, 160, 638-644.

56 F. Sun, J. Gao, Y. Zhu, X. Pi, L. Wang, X. Liu and Y. Qin, Sci. Rep., 2017, 7, 40990.

57 Y. Xiao, M. Cao, L. Ren and C. Hu, Nanoscale, 2012, 4, 74697474.

58 J. Hwang, C. Jo, M. G. Kim, J. Chun, E. Lim, S. Kim, S. Jeong, Y. Kim and J. Lee, ACS Nano, 2015, 9, 5299-5309.

59 D. Hoshi, T. Watanabe and T. Ohba, Tanso, 2017, 280, 198202.

60 H. Itoi, H. Nishihara, S. Kobayashi, S. Ittisanronnachai, T. Ishii, R. Berenguer, M. Ito, D. Matsumura and T. Kyotani, J. Phys. Chem. C, 2017, 121, 7892-7902.

61 T. Kimata, S. Kato, T. Yamaki, S. Yamamoto, T. Kobayashi and T. Terai, Surf. Coat. Technol., 2016, 306, 123-126.

62 M. Inagaki, T. Tsumura, T. Kinumoto and M. Toyoda, Carbon, 2019, 141, 580-607.

63 Y. Zheng, Y. Jiao, J. Chen, J. Liu, J. Liang, A. Du, W. Zhang, Z. Zhu, S. C. Smith, M. Jaroniec, G. Q. Lu and S. Z. Qiao, J. Am. Chem. Soc., 2011, 133, 20116-20119.

64 J. Balach, H. K. Singh, S. Gomoll, T. Jaumann, M. Klose, S. Oswald, M. Richter, J. Eckert and L. Giebeler, ACS Appl. Mater. Interfaces, 2016, 8, 14586-14595.
65 Z. Sun, J. Zhang, L. Yin, G. Hu, R. Fang, H.-M. Cheng and F. Li, Nat. Commun., 2017, 8, 14627.

66 H. Zhang, Z. Zhao, Y.-N. Hou, Y. Tang, Y. Dong, S. Wang, X. Hu, Z. Zhang, X. Wang and J. Qiu, J. Mater. Chem. A, 2018, 6, 7133-7141.

67 M. E. Casco, J. Silvestre-Albero, A. J. Ramírez-Cuesta, F. Rey, J. L. Jordá, A. Bansode, A. Urakawa, I. Peral, M. MartínezEscandell, K. Kaneko and F. Rodríguez-Reinoso, Nat. Commun., 2015, 6, 6432.

68 M. Inagaki, Carbon, 2012, 50, 3247-3266.

69 S. Iwamura, H. Nishihara and T. Kyotani, J. Power Sources, 2013, 222, 400-409.

70 T. Kasukabe, H. Nishihara, S. Iwamura and T. Kyotani, J. Power Sources, 2016, 319, 99-103.

71 T. Kasukabe, H. Nishihara, K. Kimura, T. Matsumoto, H. Kobayashi, M. Okai and T. Kyotani, Sci. Rep., 2017, 7, 42734.

72 J. Ryu, T. Chen, T. Bok, G. Song, J. Ma, C. Hwang, L. Luo, H.-K. Song, J. Cho, C. Wang, S. Zhang and S. Park, Nat. Commun., 2018, 9, 2924.

73 R. Yi, S. Chen, J. Song, M. L. Gordin, A. Manivannan and D. Wang, Adv. Funct. Mater., 2014, 24, 7433-7439.

74 M. Choi, J.-C. Kim and D.-W. Kim, Sci. Rep., 2018, 8, 960.

75 S. K. Kim, H. Kim, H. Chang, B.-G. Cho, J. Huang, H. Yoo, H. Kim and H. D. Jang, Sci. Rep., 2016, 6, 33688.

76 T. D. Bogart, D. Oka, X. Lu, M. Gu, C. Wang and B. A. Korgel, ACS Nano, 2014, 8, 915-922.

77 R. Satish, V. Aravindan, W. C. Ling and S. Madhavi, J. Power Sources, 2015, 281, 310-317.

78 S.-C. Yin, H. Grondey, P. Strobel, H. Huang and L. F. Nazar, J. Am. Chem. Soc., 2003, 125, 326-327.

79 S. C. Yin, H. Grondey, P. Strobel, M. Anne and L. F. Nazar, J. Am. Chem. Soc., 2003, 125, 10402-10411.

80 K. Karthikeyan, V. Aravindan, S. B. Lee, I. C. Jang, H. H. Lim, G. J. Park, M. Yoshio and Y. S. Lee, J. Power Sources, 2010, 195, 3761-3764.

81 K. Karthikeyan, V. Aravindan, S. B. Lee, I. C. Jang, H. H. Lim, G. J. Park, M. Yoshio and Y. S. Lee, J. Alloys Compd., 2010, 504, 224-227.

82 J.-R. Yoon, E. Baek, H.-K. Kim, M. Pecht and S.-H. Lee, Carbon, 2016, 101, 9-15.

83 S. Niu, W. Lv, C. Zhang, F. Li, L. Tang, Y. He, B. Li, Q.-H. Yang and F. Kang, J. Mater. Chem. A, 2015, 3, 20218-20224. 